\title{
1 MEAN FLOW THROUGH UTILITY SCALE SOLAR FACILITIES AND \\ 2 PRELIMINARY INSIGHTS ON DUST IMPACTS
}

3 V. Etyemezian ${ }^{a^{*}}$ a, G. Nikolich ${ }^{a}$, and J.A. Gillies ${ }^{b}$

$4 \quad{ }^{a}$ Desert Research Institute, Division of Atmospheric Sciences, 755 E. Flamingo Rd., Las Vegas, NV 89119. Tel:

5 (702) 862-5569; Fax: (702) 862-5507; E-mail: vic@ dri.edu.

$6 \quad{ }^{\mathrm{b}}$ Desert Research Institute, Division of Atmospheric Sciences, 2215 Raggio Parkway, Reno, NV 89512

\section{ABSTRACT}

Deposition of dust on solar collectors has the potential to be a costly part of utility-scale solar energy

11 production operation and maintenance. Large facilities are frequently located in arid regions with dusty soils. The orientation of solar fields with respect to the wind may affect how vulnerable or protected the soil surface is from

13 the erosive power of the wind. Field measurements of wind flow through a utility-scale solar photovoltaic facility

14 are presented. Multiple measurements of wind speed by spinning cup anemometer and wind direction by rotating vane were collected between consecutive rows of panels at two heights above the ground. This dataset provides

16 preliminary insight into the mean flow field for a nominally two-dimensional solar array. A better understanding of

17 non-steady flow components, turbulence, and conditions for the initiation of sand transport is needed for accurate

18 prediction of dust impacts of such facilities.

Keywords: Deposition, soiling, roughness, fence 


\section{INTRODUCTION}

Many of the world's regions with high grade solar resources are also regions that are arid and prone to dustiness (Mani and Pillai, 2010). Dust deposition on solar photovoltaic (PV) and solar concentrating (CS) devices has been increasingly recognized as potentially deleterious to power production (El-Shobokshy and Hussein, 1993; Sarver et al., 2013; Sayyah et al., 2014). This is of considerable concern in the Middle East and especially the Arabian Peninsula (Adinoyi and Said, 2013; Al-Hasan and Ghoneim, 2005; Charabi and Gastli, 2012; Ghazi et al., 2014; Hegazy, 2001; Khonkar et al., 2014; Qasem et al., 2014; Said and Walwil, 2014; Touati et al., 2013) as well as countries along the Mediterranean (Kalogirou et al., 2013; Piliougine et al., 2013; Schill et al., 2015; Vivar et al., 2008; Zorrilla-Casanova et al., 2012). However, there have been studies of the effects of dust on PV power production in a variety of other geographical locations including North and South America (Boyle et al., 2015; Cabanillas and Munguía, 2011; Fuentealba et al., 2015; Michels et al., 2015), Central Europe (Appels et al., 2013; Klugmann-Radziemska, 2015), Asia (Xiao et al., 2013), and even Mars (Tanabe, 2008).

Within desert landforms there are order of magnitude differences in the susceptibility to wind erosion between surfaces of different geomorphic classification (Sweeney et al., 2011). Many desert surfaces, especially those with high silt and clay contents become much more prone to wind erosion when they are mechanically disturbed (Houser and Nickling, 2001; Macpherson et al., 2008) as is routinely the case when utility-scale solar (USS) facilities are built. These surfaces then become potential sources of dust within the USS. For these reasons, many USS facilities apply chemical soil stabilizers as a matter of good practice, which can reduce emission potential of dust by orders of magnitude - at least temporarily (Kavouras et al., 2009). However, this may be costly and have negative effects on the ecosystem when applied on such large scales (Hernandez et al., 2014) as well as hydrological processes such as runoff and erosion.

Related to this, the deposition of suspended particles such as dust (especially those larger than half a micron or so in diameter) onto an object is dependent on the amount of acceleration and turbulence the dust experiences when being directed towards the object (Zhang and Shao, 2014). Prior work that has considered wind effects on dust deposition on individual solar energy devices underscores the importance of the magnitude of the incident speed of dust-laden air as well as the direction with respect to elements of a solar collector (Goossens et al., 1993; Goossens and Van Kerschaever, 1999). 
In this paper, we examine the mean wind flow through the rows of solar PV collectors within a large, USS facility. Ultimately, the interaction between wind and the solar field is the driving force for dust emission locally, dust deposition onto collectors, and the possible need for application of soil stabilizers. A medium-term goal for this type of research is to support the development of a model that can assist developers of USS facilities in estimating the operation and maintenance $(\mathrm{O} \& \mathrm{M})$ costs as they relate to issues of dust impacts on facility operation. The measurements presented here are unique and provide preliminary, insight into relationships between ambient wind and USS mean flow fields as well as test data for comparison with numerical flow models and wind tunnel results.

\section{METHODS}

Wind parameters were measured at a large USS PV facility (the PV Facility, hereafter) near Las Vegas, Nevada, USA (Figure 1). Measurements were conducted at three locations within the PV Facility. The first and second measurement locations (PV1 and PV2, respectively) corresponded to two different locations deep within the PV Facility. The third was intended to represent the upwind conditions in the absence of the PV Facility (UW). "Upwind" in this instance should not be interpreted as literally upwind, but rather as minimally influenced by the presence of the array. Depending on wind direction the UW location could in fact be downwind of the solar array. However, even in such instances, it is likely that the wind speeds measured at UW are approaching those of the flow if it was unimpeded by the array. This is because the heights of the array elements are on the order of 1.8 meters while the distance between the UW location and the edge of the array is on the order of 140 meters, so that the wind would have traveled the equivalent of about 80 times the physical roughness of the solar array before reaching the UW station. By similar argument, the measurements at PV1 and PV2 are only representative of the flow regime deep within the array and little or no information about the flows near the edges of the array can be gleaned from them. Thus, the results of this study are applicable to the large interior region of the array, where flows are relatively invariant with distance, but not to the perimeter of the array where there may be large differences between successive rows. 

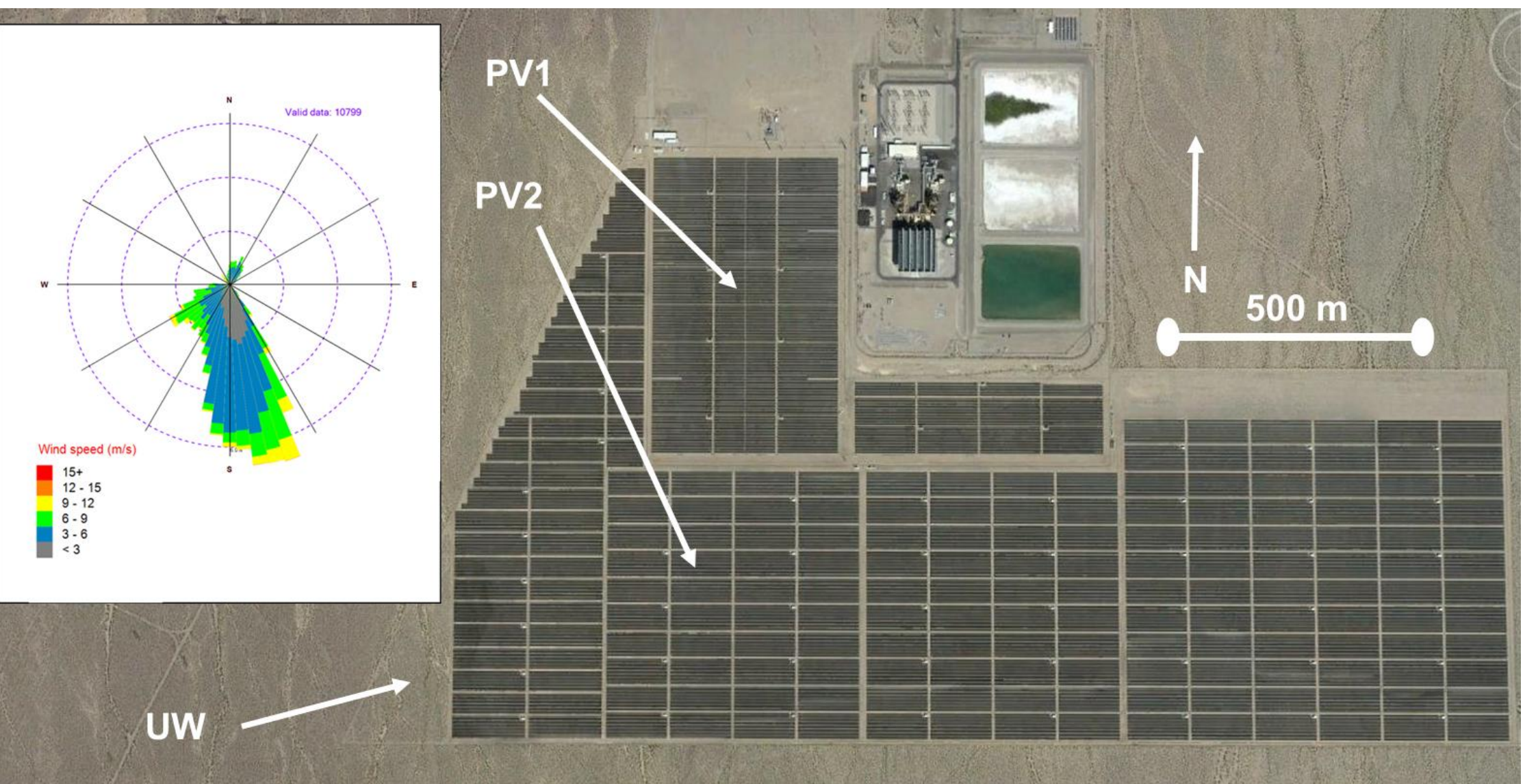

72

Figure 1. Overview of experimental site showing locations of upwind site (UW) and two within-array sites (PV1 and PV2). 
The arrays of instruments at PV1 and PV2 were located between successive rows of solar panels. The basic, contiguous unit within each row was a section that approximately $120 \mathrm{~m}$ in length with the distance between rows (on the order of 3 meters) varying slightly between PV1 and PV2. For maintenance purposes, every 20 rows in PV1 and every 14 rows in PV2, the inter-row spacing increases to about 6 meters in order to allow for the passage of maintenance vehicles. At the end of each contiguous string of solar panels that constitute a row section, a space of 4 meters to 6 meters has been left before the next row section continues the row, again for the purpose of maintaining the facility. Given that the length to width ratio between rows is about $40(120 \mathrm{~m} / 3 \mathrm{~m})$ and the break in between row sections is small compared to the length of the row sections, the solar array was assumed to provide an essentially two-dimensional obstruction to the flow.

The configuration of specific measurement instruments are provided in Figure 2. All height measurements are above ground level (AGL). At the UW location, cup anemometers (Met One, model 014A) were installed at heights of $0.96 \mathrm{~m}, 1.85 \mathrm{~m}$, and $3.3 \mathrm{~m}$. These were used to obtain the wind speed profile near the ground. A combination wind speed propeller and direction vane (RM Young, model 05103) was installed at a height of $6.0 \mathrm{~m}$. This higher wind monitor was for determining wind direction and quantifying surface wind speeds well above the height of the surface roughness. Temperature and relative humidity (Campbell Scientific, CS215) were monitored at a height of $2 \mathrm{~m}$.

The PV1 and PV2 locations were instrumented similarly to one another, with some differences in the wind sensor horizontal spacings due to slightly different geometries. At each of the two locations, twelve cup anemometers (NRG Systems, 40C) were installed as shown in Figure 2, with seven at a height of $35 \mathrm{~cm}$ and five at a height of $54 \mathrm{~cm}$. In panels b and c of Figure 2, the spacing between sensors relative to one another are shown in plan and cross-sectional views, respectively. In panel $b$, horizontal distances to each sensor from the edge of the solar panels that is lowest are provided along the left side of the panel. This measurement is illustrated in panel $\mathrm{c}$ as the distance "X". The same type of information is provided for PV2 in Figure 2d and Figure 2e. 


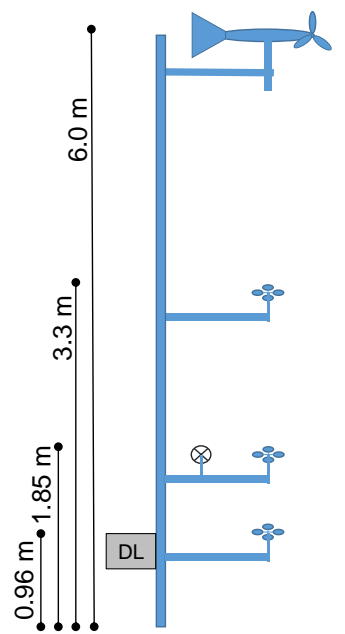

\section{Instrument Legend}

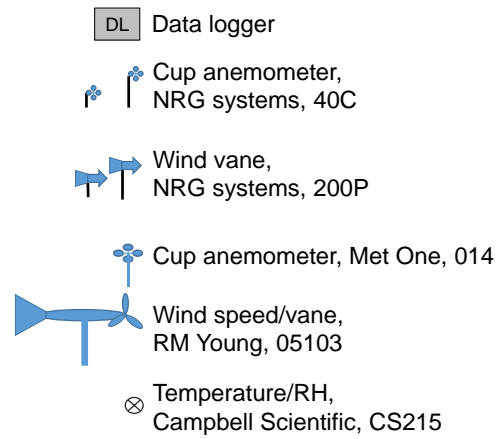

a. Upwind tower (UW) instrumentation
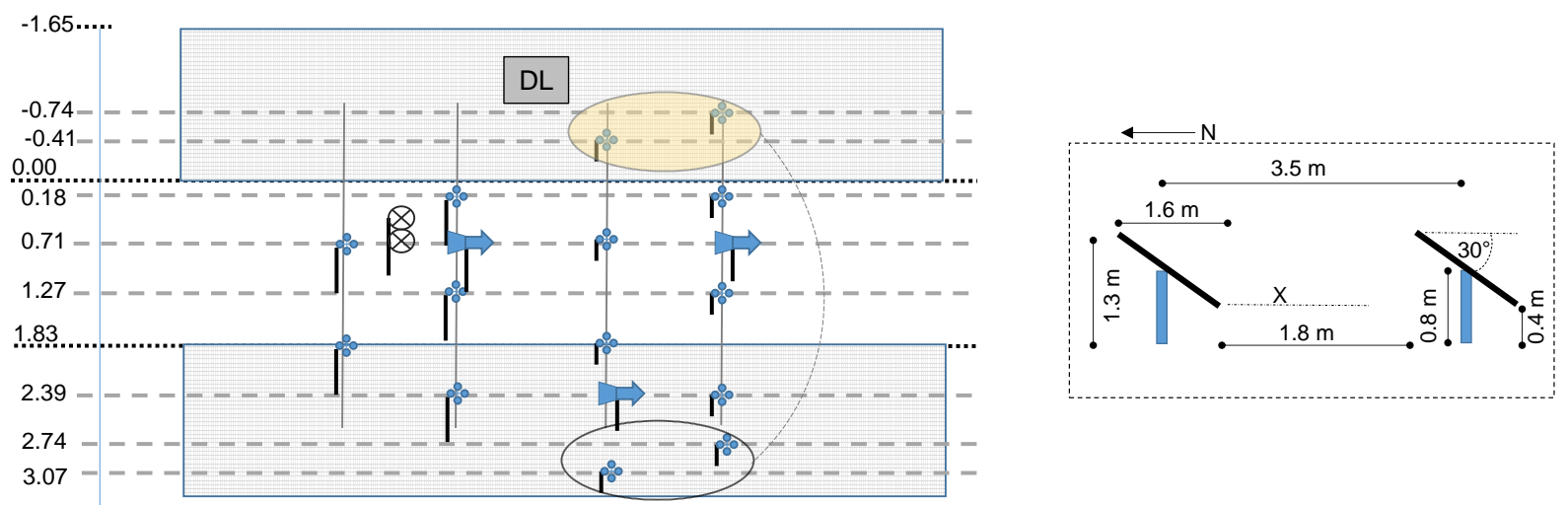

b. PV1 Instrument placement, plan view

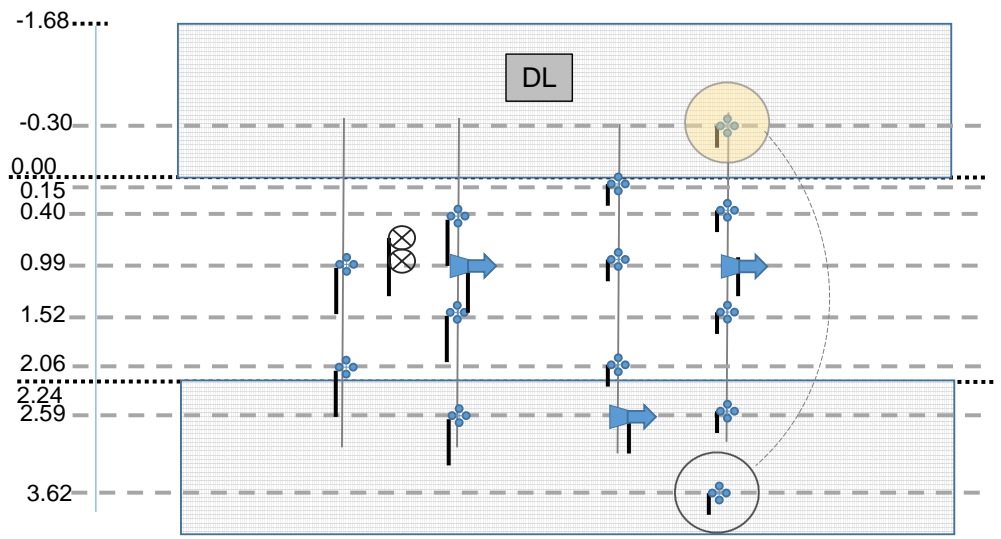

c. PV1 cross section without instruments

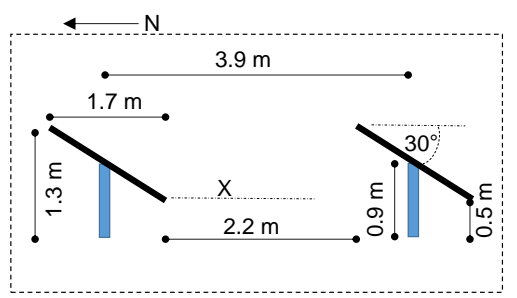

d. PV2 instrument placement, plan view

e. PV2 cross section without instruments

Figure 2. Experimental configuration of upwind tower instruments (a), instruments and module configuration at PV1 location in plan view (b) and cross section (c), and at PV2 in plan view (d) and cross section (e). Cup anemometers installed in separate rows (highlighted in panels $b$ and d) are treated as if they were in the same row as the other instruments. 

locations of the measurements were dictated to some extent by the lattice structure that was used to support the anemometers. The structure consisted of two parallel steel tracks (width $=2 \mathrm{~cm}$, height $=1.7 \mathrm{~cm}$ ) where anemometer arms could be mounted at set locations, with some ability to slide the anemometer closer or further away from the lowest edge of the solar panels. $\mathrm{cm}$ height to be located within the same row. In the PV1 array, two of the anemometers were located in the row adjacent to where the other five anemometers were, while for PV2, one anemometer was located in the adjacent row 111 to the other six anemometers. These anemometers are shaded in yellow in Figure $2 \mathrm{~b}$ and Figure $2 \mathrm{~d}$, respectively. It 112 was assumed that the average flow would be essentially identical for all rows in the vicinity of the measurement 113 arrays, because the arrays were located deep within the solar facility, so that the flow would be at its long-fetch 114 equilibrium. While the instantaneous wind vectors within successive rows are certainly different, there is no reason

115 to believe that average flows should differ greatly among rows. Therefore, the anemometers that are shaded in 116 Figure $2 \mathrm{~b}$ and Figure $2 \mathrm{~d}$, are treated as though they are located in the same rows as the other $35 \mathrm{~cm}$ height 117 anemometers (i.e., treated as if they were located in the open circle shown in the figures). With this assumption in 118 mind, the $35 \mathrm{~cm}$ height anemometers at PV1 were installed at horizontal distances from the lowest edge of the solar 119 panel of $0.18 \mathrm{~m}, 0.71 \mathrm{~m}, 1.27 \mathrm{~m}, 1.83 \mathrm{~m}, 2.39 \mathrm{~m}, 2.74 \mathrm{~m}$ (actually at $-0.74 \mathrm{~m})$, and $3.07 \mathrm{~m}(-0.41 \mathrm{~m})$ while at PV2 120 the distances from the lowest edge were $0.15 \mathrm{~m}, 0.40 \mathrm{~m}, 0.99 \mathrm{~m}, 1.52 \mathrm{~m}, 2.06 \mathrm{~m}, 2.59 \mathrm{~m}$, and $3.62 \mathrm{~m}$ (actually at $1210.31 \mathrm{~m}$ ). Two wind vanes (NRG Systems, 200P) were installed at a height of $35 \mathrm{~cm}$ (at $0.71 \mathrm{~m}$ and $2.39 \mathrm{~m}$ for PV1 and $0.99 \mathrm{~m}$ and $2.59 \mathrm{~m}$ for PV2)

All of the anemometers at a height of $54 \mathrm{~cm}$ had a matching anemometer - in terms of location between rows of solar panels - at a height of $35 \mathrm{~cm}$. At PV1, they were located at distances of $0.18 \mathrm{~m}, 0.71 \mathrm{~m}, 1.27 \mathrm{~m}, 1.83$ $\mathrm{m}$, and 2.39 , whereas at PV2 they were at $0.40 \mathrm{~m}, 0.99 \mathrm{~m}, 1.52 \mathrm{~m}, 2.06 \mathrm{~m}$, and $2.59 \mathrm{~m}$ from the lowest edge. In addition, a single wind vane - to match the position of one of the other two wind vanes at $35 \mathrm{~cm}-$ was installed at a

127 height of $54 \mathrm{~cm}$ (at 0.71 at PV1 and 0.99 at PV2). In addition to wind measurements, PV1 and PV2 were 
were all mounted on a second lattice that also consisted of two parallel steel tracks. The second lattice was offset in the along-row direction by about 4 meters from the lattice that held the $35 \mathrm{~cm}$ height instruments.

Data from all three locations were recorded in 10-minute intervals and stored on a memory card. Memory cards were retrieved and replaced and the stations were visually examined twice per year over the duration of the study (July 2012 through February 2015).

\subsection{Theory}

\subsubsection{Wind flow around two-dimensional obstructions}

Many of the qualitative characteristics of the results of this study are anticipated by a significant body of work on turbulent, essentially 2-Dimensional flows around flat bluff bodies (e.g., Bearman, 1971; Castro, 1981) with much of the work on upright wind fences being most relevant (Giannoulis et al., 2012; Jacobs, 1984; Judd et al., 1996; McAneney and Judd, 1991; Raine and Stevenson, 1977; Santiago et al., 2007; Wilson, 2004). Rows of solar panels resemble rows of windbreaks (including fences), with the differences being that solar panels are generally raised above ground level, tilted with respect to the vertical, spaced together much more closely than windbreaks, and are essentially solid (i.e., not porous). There is significant evidence from wind tunnel studies (Judd et al., 1996), numerical simulations (Wilson and Yee, 2003), and field studies (McAneney and Judd, 1991) that within a distance equivalent to $10-20$ heights of the windbreak, the wind profile between successive rows of windbreaks does not change with additional distance into the array. We presume the same is true for arrays of solar panels and note that the height of the rows of solar panels is on the order of a meter while the length of a USS is on the order of a kilometer so that the overwhelming majority of a USS will consist of what can be considered to be an interior region where edge effects of the USS are not felt by the array or by the wind.

Shademan et al., (2014) used computational fluid dynamics (CFD) to examine the flow over solar panels that were tilted at $45^{\circ}$ (somewhat larger than typical tilt angles for USS located in sun-rich areas), but most of their results pertain to gap spacing between solar panels within a row and the effect of wind incidence angle on the flow around individual rows (i.e., not in a sequence). They did investigate the effect of placing tilted solar panels in a series of rows, but the results reported mostly pertain to wind loading, although the streamlines depicted are helpful in visualizing the flow. Several other investigators (e.g., Schellenberg et al., 2013; Stathopoulos et al., 2014) have 
considered the problem principally from the standpoint of wind loading. Perhaps the most relevant prior work to that reported herein is a wind tunnel investigation (Warsido et al., 2014) that specifically examined the influence of spacing between successive rows of solar panels on wind loading effects. In that study, the models used were a 1:30 scale of a realistic PV USS facility with panels tilted at $25^{\circ}$. Those authors provide a thorough accounting of wind loading effects of row location within the array, wind direction, inter-row spacing and a number of other factors. However, there is no information provided about near-ground wind speeds that can be directly used to understand how the presence of the USS might affect wind erosion potential. Jubayer and Hangan (2016) report on results of a numerical model that considers the flow between successive rows of solar panels.

\subsubsection{Dust emission}

Dust is the suspendable fraction of the surface soil that can travel distances of tens of meters up to hundreds of kilometers once airborne. Though there is no standard size cutoff, in practice, this often means that dust consists of geological particles that have a diameter nominally smaller than 30 micrometers $(\mu \mathrm{m})$. The dominant mechanism of dust emissions occur through sandblasting of the surface by saltating particles rather than by direct entrainment of dust-sized particles (Gomes et al., 1990; Shao, 2001). This is because the balance of aerodynamic lifting force that works to entrain a particle and the inter-particle binding forces that tend to keep the particle at the ground, including gravity, favors entrainment for soil particles that are on the order of $100 \mu \mathrm{m}$ in size (Bagnold, 1941; Loosmore and Hunt, 2000; Shao and Raupach, 1993) . The minimum wind conditions that result in the sustained motion of saltating sand grains are characterized by the threshold friction velocity $u_{*_{t}}$ and the magnitude of emissions is modeled as increasing nonlinearly with increases in $u_{*}$ past the threshold through a formulation that varies slightly from author to author but is exemplified by

$\boldsymbol{F}=\mathbf{0}$ for $\boldsymbol{u}_{*}<\boldsymbol{u}_{* t} ; \boldsymbol{F}=\boldsymbol{C}\left(\boldsymbol{u}_{*}-\boldsymbol{u}_{* t}\right)^{a}$ for $\boldsymbol{u}_{*} \geq \boldsymbol{u}_{* t}$

\section{Equation 1}

where $F$ is the emission of dust in units of mass per unit area per unit time, and $\mathrm{C}$ is either a constant or a function of $u_{* t}$ and $u_{*}$, and $a$ is a positive constant. The value of $a$ is generally larger than 2 so that emissions increase rapidly with $u_{*}$ once $u_{*_{t}}$ is exceeded (e.g., King et al., 2011; Shao and Raupach, 1993). When objects such as rocks, vegetation or other non-erodible elements are on the surface in some density, then the parameterization of dust emission becomes more complex as the non-erodible elements provide the erodible surface protection from the wind under some circumstances or enhanced erosion through scouring where the flow experiences sharp changes such as 
when following flow lines around obstacles (Lu et al., 2005; Raupach et al., 1993; Shao and Yang, 2008). However, the basic principle still applies. That is, when wind speeds are high close to the ground, there is the potential for wind erosion.

\subsection{Calculation}

The $u *$ for the upwind flow was calculated using the 10-minute average wind speed profile data from the UW station. The anemometer at the top of the tower at UW is a different device (propeller type) than those used at the lower heights (cup type) and was not used to estimate $u_{*}$ to avoid the introduction of errors. One cup anemometer exhibited problematic behavior within a few months of installation and was replaced in December 2012. The third highest cup anemometer began exhibiting the signs of a worn bearing by mid-July 2013 and was not replaced. Therefore, the period of record that contains valid data from the three identical anemometers was taken to be December 10, 2012 to June 30, 2013. To ensure only quality estimates of $u_{*}$, if the standard deviation of the wind direction was $>15^{\circ}$ over a 10 -minute interval, the ratio of maximum 1 -second wind speed to the average wind speed was $>2$, or the wind speed at the top anemometer was $<2 \mathrm{~m} \mathrm{~s}^{-1}$, then $u *$ for that 10 -minute interval was not calculated. These criteria were applied based on previous experience working with such data to ensure stationarity of the wind conditions over the 10-minute period. This resulted in 10,799, 10-minute intervals that were available for estimating $u *$.

Mean wind speed for each measurement height was used to calculate $u_{*}$ for each validated 10-minute interval using least squares regression to solve the law of the wall equation:

$\frac{U(z)}{u_{*}}=\frac{1}{0.4} \ln \left(\frac{z}{z_{0}}\right)$

\section{Equation 2}

where $U(z)$ is the wind speed at height $z$ and $z_{0}$ is the aerodynamic roughness height. Of the 10,799 sets of data (three $U$ values at three $z$ values, each), based on the fact that the $\mathrm{R}^{2}$ value was above 0.99 , there were 7,999 regressions that were considered valid, each providing an estimate of $u_{*}$ and $z_{0}$. Values of $z_{0}$ were grouped into wind direction bins spanning $30^{\circ}$ and averaged to determine if the value of $z_{0}$ was dependent on wind direction. The span of values of $z_{0}$ was found to be from $0.027 \mathrm{~m}$ to $0.059 \mathrm{~m}$. Similarly, values of $z_{0}$ were grouped and averaged into categories of $u *$ values, with each category spanning $0.1 \mathrm{~m} \mathrm{~s}^{-1}$ and the span was found to be $0.023 \mathrm{~m}$ to $0.049 \mathrm{~m}$. Overall, this is a fairly small range of $z_{0}$ values and the average value of $0.037 \mathrm{~m}$ was accepted as representative of 
all wind speeds and wind directions encountered over the course of the study.

Valid 10-minute data from the PV1 and PV2 arrays were grouped by the wind direction and wind speed measured at UW in order to facilitate examination of results. Here, the UW measurements are assumed to represent

211 the conditions at PV1 and PV2 if the solar arrays were not at those locations to interact with the wind. Strictly of course, measurements at UW are not an exact representation of undisturbed (no panels) flow at PV1 or PV2.

213 Moreover, because they are separated by several hundred meters, data collected at UW during a given 10-minute 214 interval are not exactly temporally representative of the undisturbed flow at PV1 or PV2 during that same 10-minute interval. We note that given that the landscape is relatively homogeneous, flat desert for several kilometers in any 216 direction from the measurement site, the UW location provides a very reasonable analog of what the wind flow would be like at the PV1 and PV2 locations if there were no solar panels there. In order to ensure that temporal differences in wind conditions between UW and PV1 and PV2 were minimal, only data that met minimum wind speed criteria (> $3 \mathrm{~m} / \mathrm{s}$ ) and that provided good fits to the law of the wall (as explained above) were considered in subsequent analyses. These constraints on the data help ensure that wind conditions were relatively steady.

Wind directions were grouped into bins spanning $30^{\circ}$ with $0^{\circ}$ representing winds that were precisely perpendicular to the PV1 and PV2 arrays that were oriented in the east-west direction (northerly winds flow from left to right in Figure 2c and Figure 2e). The six approaching wind direction bins considered were $0^{\circ}-30^{\circ}, 30^{\circ}-$ $60^{\circ}, 60^{\circ}-90^{\circ}, 90^{\circ}-120^{\circ}, 120^{\circ}-150^{\circ}, 150^{\circ}-180^{\circ}$. Wind approach angles larger than $180^{\circ}$ were included in the "mirror" opposite bins because the PV1 and PV2 arrays are essentially mirrored about the north-south axis. For example, if a 10 -minute average of wind direction was found to be $255^{\circ}$, then that data point was attributed to the $90^{\circ}-120^{\circ}$ wind approach bin $\left(360^{\circ}-255^{\circ}=105^{\circ}\right.$, which is between $\left.90^{\circ}-120^{\circ}\right)$. This was done because there were large portions of the $0-360$ wind approach spectrum that had very little data (see wind rose in Figure 1) and combining mirror opposites was the approach chosen to fill in such data gaps. The assumption of symmetry that was used to justify this approach could not be tested broadly because sufficient data to do so were only available for $150^{\circ}$

$231-180^{\circ}$ and $180^{\circ}-210^{\circ}$ mirror pair. For those two directions, the assumption of symmetry was justified, with virtually no differences in wind parameters at any of the measurement locations. 
wind speed bins that were used to subdivide data were chosen, somewhat arbitrarily to be $0-3 \mathrm{~m} / \mathrm{s}(0 \mathrm{~m} / \mathrm{s} \leq \mathrm{u} *<$ $0.24 \mathrm{~m} / \mathrm{s}), 3-6 \mathrm{~m} / \mathrm{s}\left(0.24 \mathrm{~m} / \mathrm{s} \leq \mathrm{u}_{*}<0.47 \mathrm{~m} / \mathrm{s}\right), 6-9 \mathrm{~m} / \mathrm{s}\left(0.47 \mathrm{~m} / \mathrm{s} \leq \mathrm{u}_{*}<0.71 \mathrm{~m} / \mathrm{s}\right)$, and greater than $9 \mathrm{~m} / \mathrm{s}\left(\mathrm{u}_{*}>\right.$ $0.71 \mathrm{~m} / \mathrm{s}$ ). Each valid data point from PV1 and PV2 was associated with the wind speed and wind direction bin measured at UW during the same 10-minute interval. No attempt was made to try to offset the time to account for travel distance between UW and either PV1 or PV2. For this component, all valid wind speed measurements at UW were used (i.e., regardless of how well the wind speed profile obeyed a law of the wall profile). If the UW wind direction was mirrored to fit into one of the wind direction bins that span from $0^{\circ}-180^{\circ}$, then the wind direction data from PV1 and PV2 were also mirrored.

The wind speed in the unobstructed flow was calculated from the UW tower data using Equation 1, with a $z$ value of $0.35 \mathrm{~m}$ for the lower anemometers in the PV1 and PV2 arrays and $0.54 \mathrm{~m}$ for the upper anemometers. The unobstructed wind speed was used to normalize the actual wind speed measured by anemometers in PV1 and PV2 (i.e., $\mathrm{PV} 1_{\mathrm{x}, \mathrm{z}} / \mathrm{UW}_{\mathrm{z}}$. and $\mathrm{PV} 2_{\mathrm{x}, \mathrm{z}} / \mathrm{UW}_{\mathrm{z}}$ ). These normalized values are used to construct "attenuation rose" diagrams as explained in Figure 3a. Each attenuation rose provides an overview of how much wind speed at a measurement location within the array is attenuated compared to a location at the same height outside (UW) the array for a specific wind approach angle bin as measured at UW. The color of the traces represents different bins of wind speed at UW. These attenuation roses are all symmetrical about the $0^{\circ}-180^{\circ}$ line because data have been combined for mirror opposite wind approach angle bins.

Representation of the wind direction shifts and wind speed reduction for individual 10-minute intervals is explained in Figure 3b. Here, 10-minute data were color-coded based on the wind speed at UW (blue for $3-6 \mathrm{~m} / \mathrm{s}$, green for $6-9 \mathrm{~m} / \mathrm{s}$, yellow for $9-12 \mathrm{~m} / \mathrm{s}$, and orange for $>12 \mathrm{~m} / \mathrm{s}$ ). For all these types of representations, each concentric circle corresponds to an increment of $3 \mathrm{~m} / \mathrm{s}$. Data are also presented separately by wind approach angle $\left(0^{\circ}-30^{\circ}, 30^{\circ}-60^{\circ}, 60^{\circ}-90^{\circ}, 90^{\circ}-120^{\circ}, 120^{\circ}-150^{\circ}, 150^{\circ}-180^{\circ}\right)$ and as in the case of the attenuation roses, symmetry about the $0^{\circ}-180^{\circ}$ line was assumed. Therefore, for representing UW (see bottom, left inset of Figure $3 b)$, this results in the colors being segregated into a wedge that crosses concentric rings. However, for measurement locations within PV1 and PV2, the location of the colored data points (with colors representing UW conditions), indicates the wind speed and direction at the measurement location within the array. 


\section{RESULTS}

Attenuation roses for all measurement locations are shown at their correct relative spacing to the solar arrays for PV1 and PV2 in Figure 4. Directional response to varying UW wind conditions is illustrated in Figure 5 for PV1 and Figure 6 for PV2. The UW wind approach angles are shown in the upper row of panels for those two figures and data associated with specific wind speed bins at UW are grouped by color. Note that data associated with UW wind speeds lower than $3 \mathrm{~m} \mathrm{~s}^{-1}$ are not reported here because these low wind speeds result in spurious wind direction and wind speed estimates at PV1 and PV2. Additionally, due to several periods of power and other equipment failures the number of valid data points used to create the figures for PV2 was nearly double that for PV1 $(32,416$ versus 16,942$)$. Notably, the PV2 data set contains more instances of strong winds with a $30^{\circ}-60^{\circ}$ approach angle.

It is clear from Figure 4 (numeric values are reported for PV1 and PV2 in Table 1 and Table 2) that at almost all locations, the wind is least-attenuated either when the approach angle is between $60^{\circ}-90^{\circ}$ for locations farther from the low edge of the rows of panels (i.e., farther towards the bottom in Figure 4) or when the approach angle is between $90^{\circ}-120^{\circ}$ for locations closer to the low edge of the rows of panels. In some cases the data for PV2 seem to indicate that the wind speeds are increased compared to outside the array. It is not clear if this is in fact the case or a consequence of measurement artifact related to using cup anemometers, which are known to exhibit "over-speeding" in regions of turbulent flow (Kristensen, 1998; Wyngaard, 1981). In any case, it appears that when incoming wind has a strong component in the direction parallel to the rows of solar panels, at best, the surface experiences the shear stress imposed by the wind nearly at its unobstructed strength, while at worst, the solar array may be accelerating the flow. 


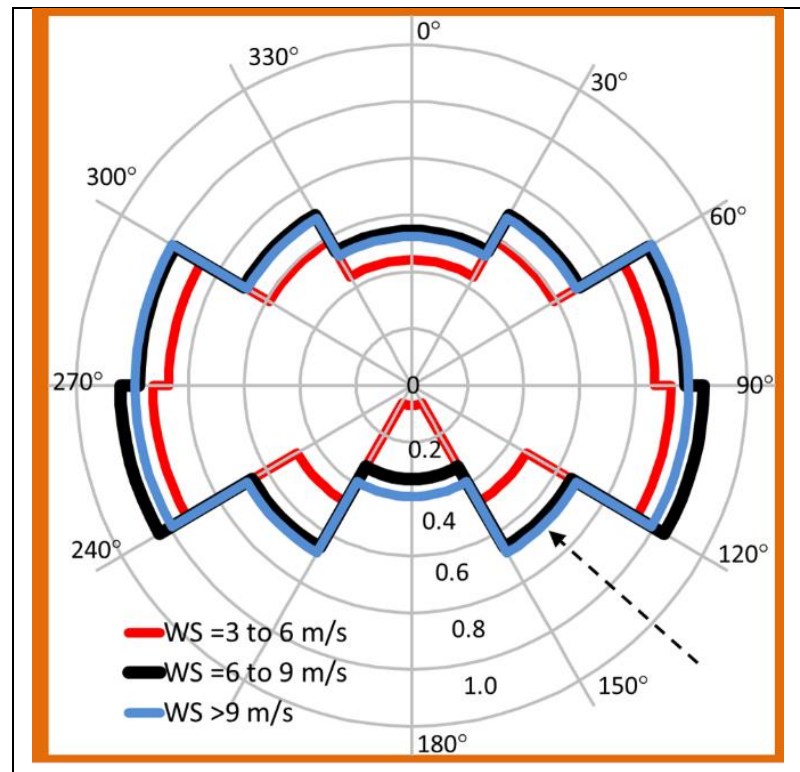

a. Attenuation rose example. Arrow to blue series indicates that when UW winds are from $120^{\circ}$ $150^{\circ}$ and $>9 \mathrm{~m} / \mathrm{s}$, average wind speed is $67 \%$ of UW value at equivalent height. Orange border indicates measurement at $54 \mathrm{~cm}$ height.

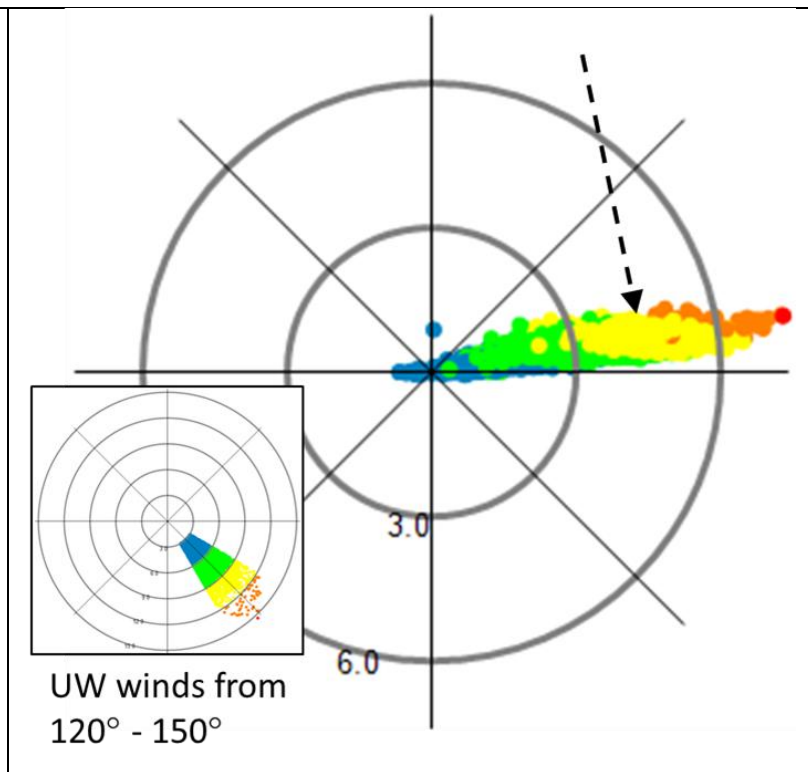

b. Directional shift example. UW winds are color coded (insert at bottom). Each circle corresponds to $3 \mathrm{~m} / \mathrm{s}$ increment. Arrow to yellow data point indicates that for a specific 10-minute interval when UW winds were $9-12 \mathrm{~m} / \mathrm{s}$ from $120^{\circ}-150^{\circ}$, wind speed within array was $4.4 \mathrm{~m} / \mathrm{s}$ from $70^{\circ}$.

Figure 3. Explanation of data presentation types. 
Table 1. Summary of Data from PV1 Array. Wind speeds measured within array normalized to those at same height at UW.

\begin{tabular}{|c|c|c|c|c|c|c|c|c|c|c|c|c|c|c|}
\hline & & $\mathrm{H}(\mathrm{m})$ & 0.36 & 0.54 & 0.36 & 0.54 & 0.36 & 0.54 & 0.36 & 0.54 & 0.36 & 0.54 & 0.36 & 0.36 \\
\hline & & $x(m)$ from low & & & & & & & & & & & $-0.41 /$ & $-0.74 /$ \\
\hline WS & WD & edge/\# data & 0.18 & 0.18 & 0.71 & 0.71 & 1.27 & 1.27 & 1.83 & 1.83 & 2.39 & 2.39 & 3.2 & 3.5 \\
\hline 3 to $6 \mathrm{~m} / \mathrm{s}$ & 0_30 & 808 & 0.6 & 0.3 & 0.6 & 0.4 & 0.5 & 0.5 & 0.5 & 0.4 & 0.5 & 0.5 & 0.3 & 0.7 \\
\hline 3 to $6 \mathrm{~m} / \mathrm{s}$ & $30 \_60$ & 445 & 0.7 & 0.6 & 0.6 & 0.6 & 0.7 & 0.6 & 0.6 & 0.6 & 0.7 & 0.6 & 0.2 & 0.7 \\
\hline 3 to $6 \mathrm{~m} / \mathrm{s}$ & 60_90 & 215 & 0.7 & 0.9 & 0.9 & 0.9 & 0.9 & 0.9 & 0.8 & 0.8 & 0.6 & 0.7 & 0.4 & 0.5 \\
\hline 3 to $6 \mathrm{~m} / \mathrm{s}$ & 90_120 & 758 & 0.9 & 1.0 & 1.0 & 0.9 & 0.9 & 0.9 & 0.6 & 0.7 & 0.5 & 0.5 & 0.3 & 0.5 \\
\hline 3 to $6 \mathrm{~m} / \mathrm{s}$ & 120_150 & 1446 & 0.4 & 0.6 & 0.5 & 0.5 & 0.4 & 0.4 & 0.2 & 0.3 & 0.2 & 0.2 & 0.1 & 0.1 \\
\hline 3 to $6 \mathrm{~m} / \mathrm{s}$ & 150_180 & 7248 & 0.0 & 0.1 & 0.1 & 0.1 & 0.0 & 0.0 & 0.0 & 0.0 & 0.0 & 0.0 & 0.0 & 0.0 \\
\hline 6 to $9 \mathrm{~m} / \mathrm{s}$ & 0_30 & 322 & 0.7 & 0.4 & 0.7 & 0.5 & 0.7 & 0.6 & 0.6 & 0.5 & 0.6 & 0.6 & 0.5 & 0.7 \\
\hline 6 to $9 \mathrm{~m} / \mathrm{s}$ & $30 \_60$ & 139 & 0.8 & 0.7 & 0.8 & 0.7 & 0.8 & 0.7 & 0.8 & 0.7 & 0.8 & 0.7 & 0.5 & 0.7 \\
\hline 6 to $9 \mathrm{~m} / \mathrm{s}$ & 60_90 & 54 & 0.9 & 1.0 & 1.0 & 1.0 & 1.0 & 1.0 & 0.9 & 0.9 & 0.8 & 0.8 & 0.6 & 0.7 \\
\hline 6 to $9 \mathrm{~m} / \mathrm{s}$ & 90_120 & 580 & 1.0 & 1.1 & 1.1 & 1.0 & 1.0 & 1.0 & 0.9 & 0.8 & 0.7 & 0.7 & 0.6 & 0.7 \\
\hline 6 to $9 \mathrm{~m} / \mathrm{s}$ & 120_150 & 958 & 0.6 & 0.8 & 0.7 & 0.7 & 0.6 & 0.6 & 0.5 & 0.4 & 0.4 & 0.4 & 0.2 & 0.4 \\
\hline 6 to $9 \mathrm{~m} / \mathrm{s}$ & 150_180 & 2499 & 0.2 & 0.5 & 0.3 & 0.3 & 0.2 & 0.2 & 0.1 & 0.1 & 0.1 & 0.1 & 0.0 & 0.1 \\
\hline$>9 \mathrm{~m} / \mathrm{s}$ & 0_30 & 5 & 0.7 & 0.4 & 0.7 & 0.5 & 0.6 & 0.5 & 0.6 & 0.5 & 0.6 & 0.5 & 0.5 & 0.7 \\
\hline$>9 \mathrm{~m} / \mathrm{s}$ & 30_60 & 35 & 0.7 & 0.6 & 0.8 & 0.7 & 0.7 & 0.7 & 0.7 & 0.7 & 0.7 & 0.7 & 0.7 & 0.7 \\
\hline$>9 \mathrm{~m} / \mathrm{s}$ & 60_90 & 1 & 0.9 & 1.0 & 1.0 & 1.0 & 1.0 & 1.0 & 1.0 & 0.9 & 0.8 & 0.8 & 0.6 & 0.7 \\
\hline$>9 \mathrm{~m} / \mathrm{s}$ & 90_120 & 54 & 1.0 & 1.1 & 1.1 & 1.0 & 1.0 & 0.9 & 0.8 & 0.8 & 0.7 & 0.6 & 0.6 & 0.7 \\
\hline$>9 \mathrm{~m} / \mathrm{s}$ & 120_150 & 199 & 0.6 & 0.8 & 0.7 & 0.7 & 0.6 & 0.6 & 0.5 & 0.5 & 0.5 & 0.4 & 0.3 & 0.4 \\
\hline$>9 \mathrm{~m} / \mathrm{s}$ & 150_180 & 726 & 0.3 & 0.5 & 0.4 & 0.4 & 0.3 & 0.3 & 0.2 & 0.2 & 0.2 & 0.2 & 0.1 & 0.2 \\
\hline All & 0_30 & 1135 & 0.7 & 0.4 & 0.6 & 0.5 & 0.6 & 0.5 & 0.5 & 0.5 & 0.6 & 0.5 & 0.4 & 0.7 \\
\hline All & 30_60 & 619 & 0.7 & 0.6 & 0.7 & 0.6 & 0.7 & 0.6 & 0.7 & 0.6 & 0.8 & 0.6 & 0.4 & 0.7 \\
\hline All & 60_90 & 270 & 0.8 & 0.9 & 0.9 & 0.9 & 0.9 & 0.9 & 0.8 & 0.8 & 0.7 & 0.7 & 0.4 & 0.6 \\
\hline All & 90_120 & 1392 & 1.0 & 1.1 & 1.1 & 1.0 & 1.0 & 0.9 & 0.8 & 0.7 & 0.6 & 0.6 & 0.4 & 0.7 \\
\hline All & 120_150 & 2603 & 0.6 & 0.7 & 0.6 & 0.6 & 0.5 & 0.5 & 0.4 & 0.4 & 0.3 & 0.3 & 0.2 & 0.3 \\
\hline All & 150_180 & 10473 & 0.1 & 0.3 & 0.2 & 0.2 & 0.1 & 0.1 & 0.1 & 0.1 & 0.1 & 0.1 & 0.0 & 0.1 \\
\hline
\end{tabular}




\begin{tabular}{|c|c|c|c|c|c|c|c|c|c|c|c|c|c|c|}
\hline & & $\mathrm{H}(\mathrm{m})$ & 0.36 & 0.36 & 0.54 & 0.36 & 0.54 & 0.36 & 0.54 & 0.36 & 0.54 & 0.36 & 0.54 & 0.36 \\
\hline WS & WD & $\begin{array}{l}x(m) \text { from low } \\
\text { edge/\# data }\end{array}$ & 0.15 & 0.40 & 0.40 & 0.99 & 0.99 & 1.52 & 1.52 & 2.06 & 2.06 & 2.59 & 2.59 & $\begin{array}{c}-0.55 / \\
3.4 \\
\end{array}$ \\
\hline 3 to $6 \mathrm{~m} / \mathrm{s}$ & 0_30 & 1795 & 0.3 & 0.4 & 0.3 & 0.4 & 0.4 & 0.6 & 0.4 & 0.5 & 0.5 & 0.5 & 0.3 & 0.4 \\
\hline 3 to $6 \mathrm{~m} / \mathrm{s}$ & $30 \_60$ & 831 & 0.4 & 0.5 & 0.5 & 0.5 & 0.5 & 0.8 & 0.5 & 0.6 & 0.6 & 0.7 & 0.4 & 0.6 \\
\hline 3 to $6 \mathrm{~m} / \mathrm{s}$ & 60_90 & 439 & 0.8 & 0.8 & 0.9 & 0.8 & 0.9 & 1.0 & 0.8 & 0.8 & 0.8 & 0.7 & 0.5 & 0.2 \\
\hline 3 to $6 \mathrm{~m} / \mathrm{s}$ & 90_120 & 1336 & 1.1 & 1.0 & 1.1 & 1.0 & 1.0 & 1.1 & 0.9 & 0.8 & 0.8 & 0.6 & 0.5 & 0.1 \\
\hline 3 to $6 \mathrm{~m} / \mathrm{s}$ & 120_150 & 2732 & 0.7 & 0.6 & 0.7 & 0.5 & 0.6 & 0.6 & 0.4 & 0.3 & 0.4 & 0.2 & 0.2 & 0.1 \\
\hline 3 to $6 \mathrm{~m} / \mathrm{s}$ & 150_180 & 14230 & 0.2 & 0.2 & 0.2 & 0.1 & 0.1 & 0.1 & 0.0 & 0.0 & 0.0 & 0.0 & 0.0 & 0.0 \\
\hline 6 to $9 \mathrm{~m} / \mathrm{s}$ & 0_30 & 735 & 0.5 & 0.6 & 0.4 & 0.6 & 0.5 & 0.6 & 0.5 & 0.6 & 0.5 & 0.6 & 0.4 & 0.6 \\
\hline 6 to $9 \mathrm{~m} / \mathrm{s}$ & $30 \_60$ & 243 & 0.6 & 0.7 & 0.6 & 0.7 & 0.7 & 0.8 & 0.7 & 0.8 & 0.7 & 0.8 & 0.6 & 0.7 \\
\hline 6 to $9 \mathrm{~m} / \mathrm{s}$ & 60_90 & 121 & 1.0 & 1.0 & 1.0 & 1.0 & 1.0 & 1.1 & 1.0 & 1.0 & 0.9 & 0.8 & 0.7 & 0.3 \\
\hline 6 to $9 \mathrm{~m} / \mathrm{s}$ & 90_120 & 1019 & 1.3 & 1.1 & 1.2 & 1.2 & 1.1 & 1.2 & 1.1 & 1.0 & 0.9 & 0.8 & 0.6 & 0.2 \\
\hline 6 to $9 \mathrm{~m} / \mathrm{s}$ & 120_150 & 1908 & 0.9 & 0.9 & 0.8 & 0.8 & 0.7 & 0.8 & 0.7 & 0.6 & 0.5 & 0.5 & 0.4 & 0.2 \\
\hline 6 to $9 \mathrm{~m} / \mathrm{s}$ & 150_180 & 4869 & 0.6 & 0.6 & 0.5 & 0.4 & 0.4 & 0.4 & 0.2 & 0.2 & 0.2 & 0.2 & 0.1 & 0.1 \\
\hline$>9 \mathrm{~m} / \mathrm{s}$ & $0 \_30$ & 30 & 0.6 & 0.7 & 0.5 & 0.7 & 0.6 & 0.7 & 0.6 & 0.7 & 0.6 & 0.7 & 0.5 & 0.5 \\
\hline$>9 \mathrm{~m} / \mathrm{s}$ & 30_60 & 66 & 0.6 & 0.7 & 0.6 & 0.7 & 0.7 & 0.7 & 0.7 & 0.7 & 0.6 & 0.7 & 0.7 & 0.5 \\
\hline$>9 \mathrm{~m} / \mathrm{s}$ & 60_90 & 2 & 1.1 & 1.0 & 1.1 & 1.1 & 1.1 & 1.1 & 1.0 & 1.0 & 0.9 & 0.8 & 0.3 & 0.3 \\
\hline$>9 \mathrm{~m} / \mathrm{s}$ & 90_120 & 180 & 1.3 & 1.2 & 1.2 & 1.2 & 1.1 & 1.1 & 1.0 & 1.0 & 0.8 & 0.8 & 0.7 & 0.3 \\
\hline$>9 \mathrm{~m} / \mathrm{s}$ & 120_150 & 560 & 1.0 & 0.9 & 0.9 & 0.8 & 0.8 & 0.8 & 0.7 & 0.7 & 0.6 & 0.6 & 0.4 & 0.3 \\
\hline$>9 \mathrm{~m} / \mathrm{s}$ & 150_180 & 1320 & 0.6 & 0.6 & 0.5 & 0.5 & 0.4 & 0.4 & 0.3 & 0.3 & 0.2 & 0.3 & 0.2 & 0.2 \\
\hline All & 0_30 & 2560 & 0.4 & 0.5 & 0.4 & 0.5 & 0.4 & 0.6 & 0.4 & 0.5 & 0.5 & 0.6 & 0.3 & 0.5 \\
\hline All & $30 \_60$ & 1140 & 0.5 & 0.6 & 0.6 & 0.6 & 0.6 & 0.8 & 0.6 & 0.7 & 0.6 & 0.7 & 0.5 & 0.6 \\
\hline All & 60_90 & 562 & 0.9 & 0.8 & 0.9 & 0.9 & 0.9 & 1.0 & 0.9 & 0.9 & 0.8 & 0.8 & 0.6 & 0.2 \\
\hline All & 90_120 & 2535 & 1.2 & 1.1 & 1.1 & 1.1 & 1.1 & 1.1 & 1.0 & 0.9 & 0.8 & 0.7 & 0.6 & 0.2 \\
\hline All & 120_150 & 5200 & 0.9 & 0.8 & 0.8 & 0.7 & 0.7 & 0.7 & 0.6 & 0.5 & 0.5 & 0.4 & 0.3 & 0.1 \\
\hline All & 150_180 & 20419 & 0.4 & 0.4 & 0.3 & 0.2 & 0.2 & 0.2 & 0.2 & 0.1 & 0.1 & 0.1 & 0.1 & 0.1 \\
\hline
\end{tabular}



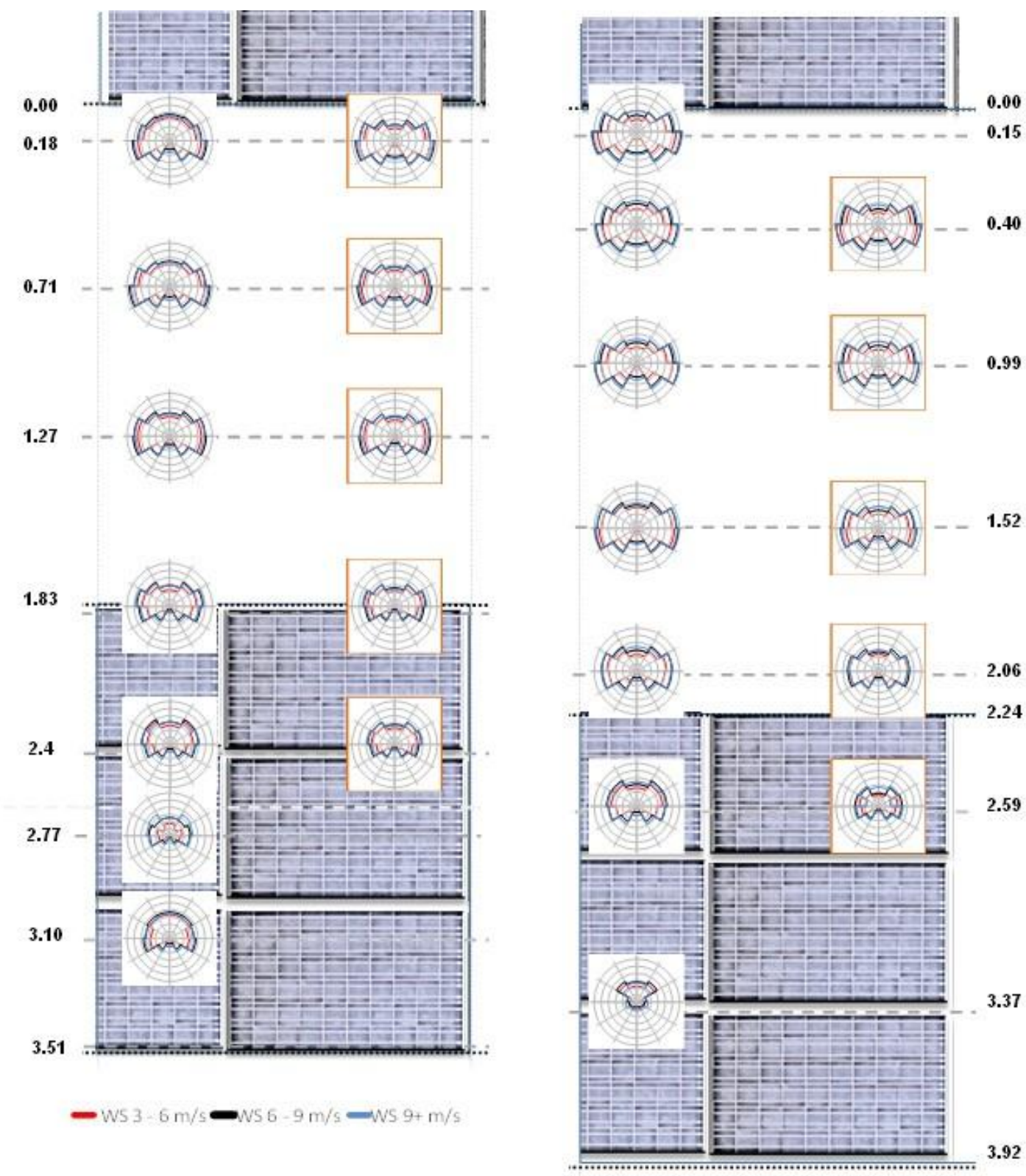

Figure 4. Attenuation roses for Arrays 1 (left) and 2 (right) by distance from low edge. Data associated with approach angles from $180^{\circ}-360^{\circ}$ have been combined with their mirror equivalents $\left(0^{\circ}-180^{\circ}\right)$, but plotted over $0^{\circ}-360^{\circ}$ assuming symmetry

289 In the case of either the $60^{\circ}-90^{\circ}$ and $90^{\circ}-120^{\circ}$ wind approach angle categories, the arrays have the effect of

290 forcing the near-ground wind to align more tightly with the direction parallel to the rows of PV panels (See Figure 5

291 and Figure 6). For example, considering the PV1 data, if only wind approach scenarios between $60^{\circ}-90^{\circ}$ are 
considered (and only wind speeds greater than $6 \mathrm{~m} \mathrm{~s}^{-1}$ to ensure that within array winds are high enough to cause the wind vanes to orient properly), the average wind approach angle is $83^{\circ}$ and the standard deviation is $7^{\circ}$. The averages within the array are similar to one another as well as the average wind approach angle (indistinguishable given the uncertainty in orienting wind vanes in the field) at all three locations where wind vanes were installed, namely $84^{\circ}, 85^{\circ}$, and $87^{\circ}$. However, the range in wind directions is much smaller than it is in the UW flow as evidenced by much smaller standard deviations of $2^{\circ}, 2^{\circ}$, and $1^{\circ}$. Similarly if only wind approach angles between $90^{\circ}-120^{\circ}$ are considered, the average UW wind approach angle is $108^{\circ}$ and the standard deviation is $8^{\circ}$. The wind directions within the PV1 array were $82^{\circ}, 87^{\circ}$, and $88^{\circ}$ with standard deviations of $2^{\circ}, 1^{\circ}$, and $1^{\circ}$. As with $60^{\circ}-90^{\circ}$ approach winds, the standard deviations of wind direction are much smaller within the PV1 array indicating that the flow is forced to align with the direction parallel to the solar arrays. Moreover, in the case of the $90^{\circ}-120^{\circ}$ wind approach angle, the flow near the ground exhibits a slightly northerly component even though the approach flow does not. We note that the same features of winds approaching from the $60^{\circ}-90^{\circ}$ and $90^{\circ}-120^{\circ}$ are observed for the PV2 array, although they are slightly less pronounced.

For southerly winds, which are nearly perpendicular to the rows of panels $\left(150^{\circ}-180^{\circ}\right)$ and along the front face of the panels, the attenuation of winds is maximal regardless of horizontal or vertical location. The lowest anemometers $(0.36 \mathrm{~m})$ registered wind speeds that were as low as $1 \%$ and as high as $64 \%$ of the upwind value at the same height, with the majority of locations exhibiting winds that were less than $45 \%$ of the upwind values. Under these conditions, the wind can be envisioned as being directed away from the ground because of the upward pitch of the rows of panels. This characterization is supported by the data shown in Figure 5 and Figure 6 for the $150^{\circ}-180^{\circ}$ approach angles. Winds speeds at the three locations within PV1 and PV2 where wind direction was also measured indicate that the magnitude of the wind speed is greatly attenuated and that the wind direction is offset by $90^{\circ}$ to $270^{\circ}$ compared to the upwind conditions so that the resultant winds within the array range between $270^{\circ}$ to $90^{\circ}$. This suggests that for southerly winds, there is a counter flow that may be caused by a recirculation pattern between successive rows of solar panels. This can be conceptualized as shown in Figure 7a. 


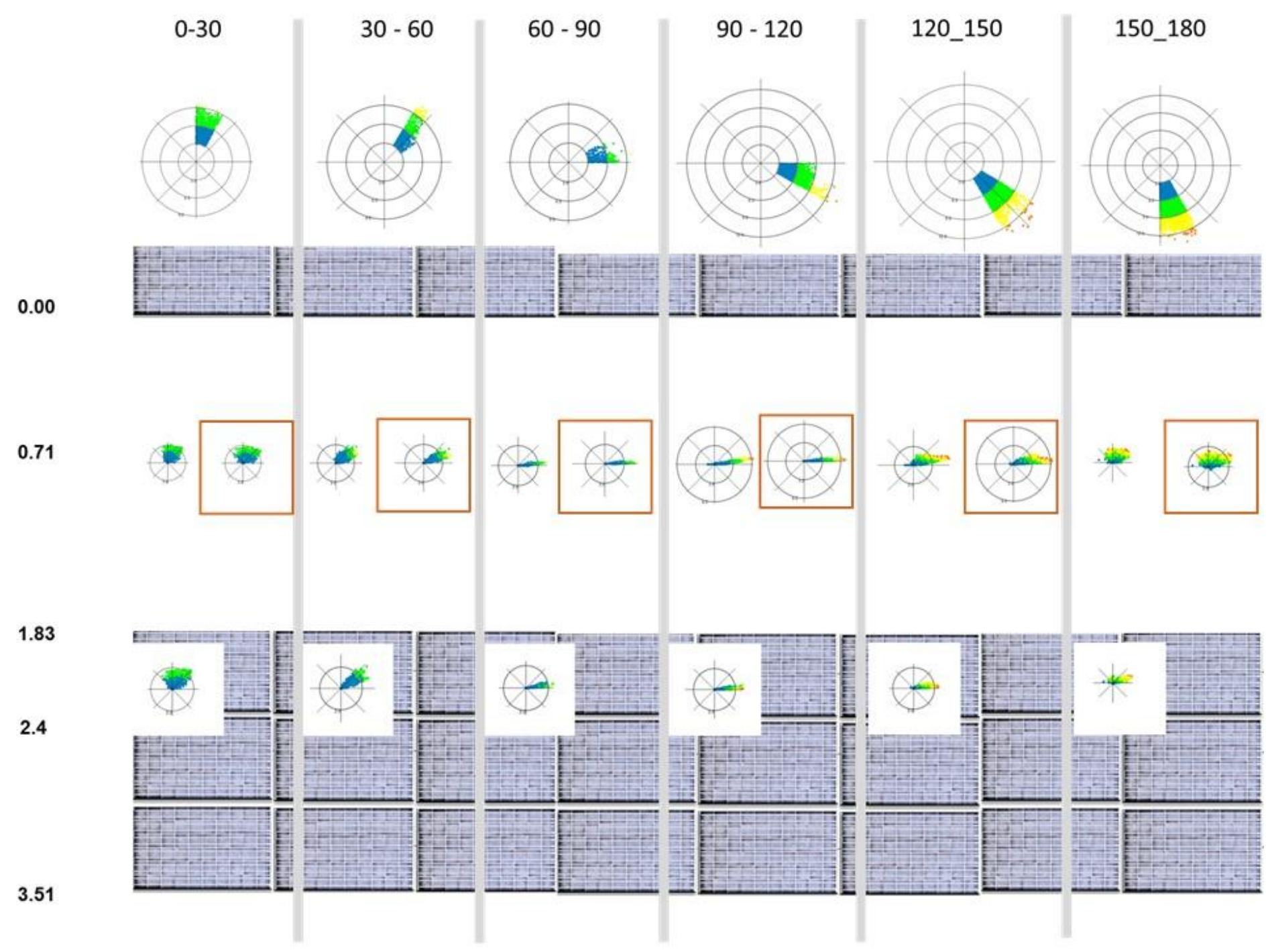

Figure 5. Wind roses in PV1 in response to wind conditions at upwind station. Circles represent units of $3 \mathrm{~m} / \mathrm{s}$. Data associated with approach angles from $180^{\circ}-360^{\circ}$ have been combined with their mirror equivalents and plotted over $0^{\circ}-180^{\circ}$ assuming symmetry. 


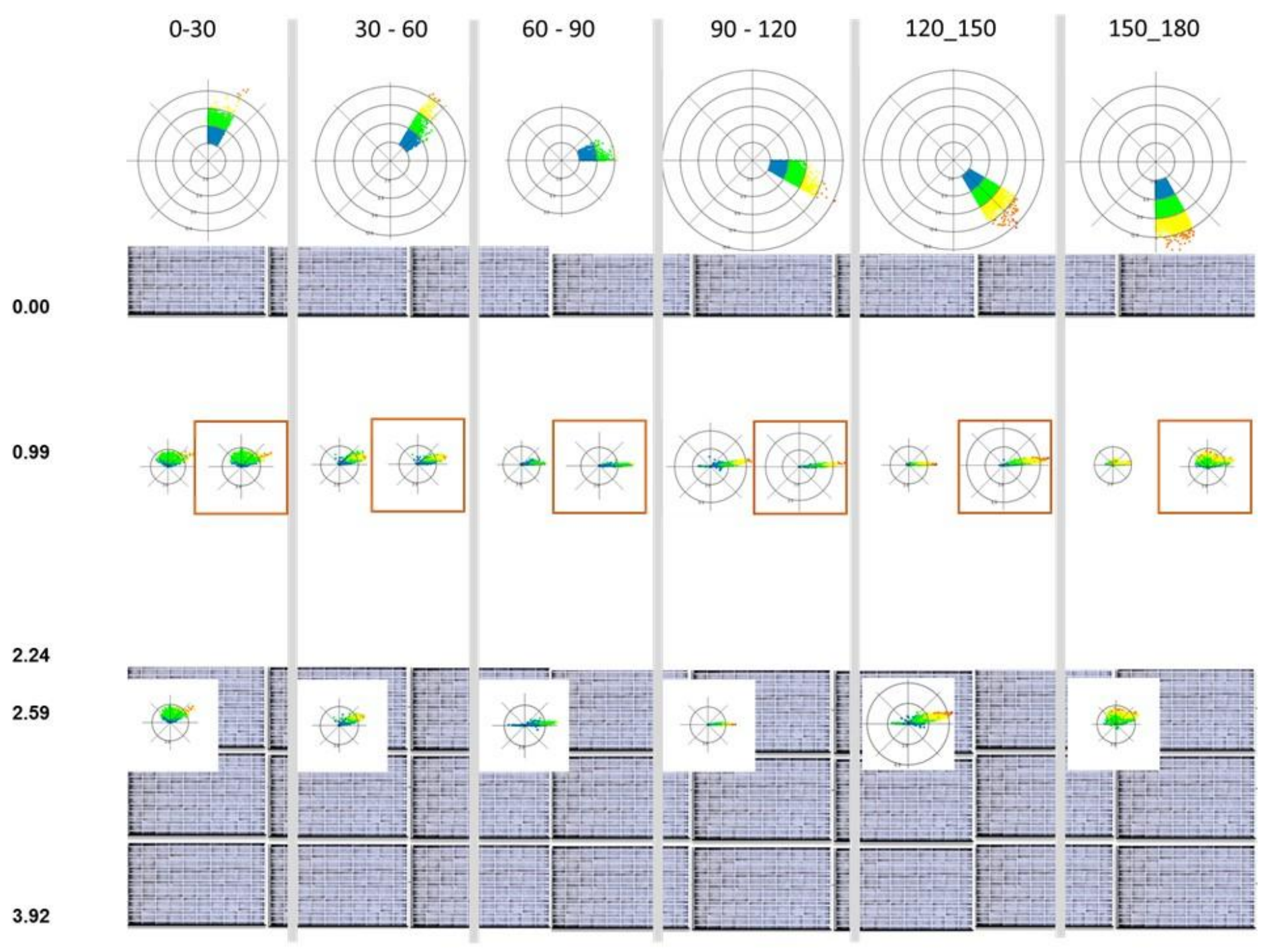

Figure 6. Wind roses in PV2 in response to wind conditions at upwind station. Circles represent units of $3 \mathrm{~m} / \mathrm{s}$. Data associated with approach angles from $180^{\circ}-360^{\circ}$ have been combined with their mirror equivalents and plotted over $0^{\circ}-180^{\circ}$ assuming symmetry. 


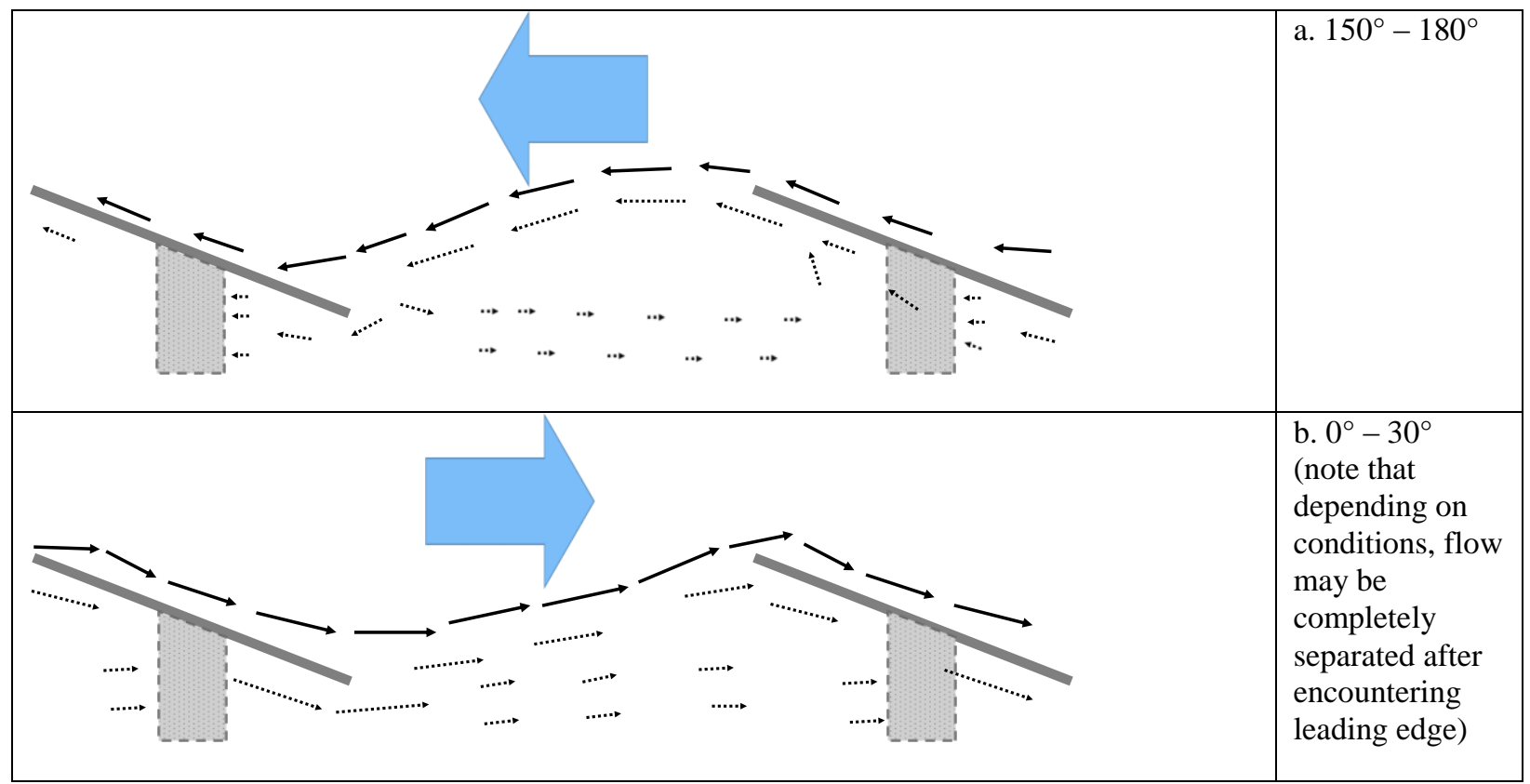

Figure 7. Conceptual models for flow between consecutive rows of solar panels. Solid arrows represent the primary flow lines above the array elements while dashed arrows represent flow response within the array. Large arrows illustrate components of approach flow when viewed from above the array.

While still perpendicular to the solar panel arrays, winds approaching from $0^{\circ}-30^{\circ}$ are not nearly as well attenuated near the ground between subsequent rows of panels as are winds approaching between $150^{\circ}-180^{\circ}$. Depending on location within the array, the lowest anemometers registered wind speeds that were as low as 33\% and as high as $74 \%$ of the upwind value at the same height, with the majority of locations exhibiting winds that were $>50 \%$ of the upwind values. Considering the previous discussion, it seems plausible that the main features of flow between successive rows of panels when the wind approach angle is between $0^{\circ}-30^{\circ}$ is represented in Figure $7 \mathrm{~b}$. The data in Figure 5 and Figure 6 indicate that near-ground winds retain much of the northerly component of the incident wind (i.e., northerly winds aloft translate into northerly winds within array), although they do spread considerably about the upwind approach values. Within this wind incidence regime, the average incoming wind direction is $14^{\circ}$ with a standard deviation of $9^{\circ}$. In PV1 the average wind directions at the three locations where a wind vane is emplaced are $18^{\circ}, 27^{\circ}$, and $33^{\circ}$, and standard deviations are $21^{\circ}, 22^{\circ}$, and $26^{\circ}$. Here again, there is evidence that the arrays exert an influence on the near-ground flow by forcing alignment with direction of the rows. However, the comparatively high standard deviations suggest that this forcing is perhaps intermittent and fluctuates in direction (i.e., alternates in direction from east to west). No measurements are available to directly support this hypothesis as upwind conditions are separated in time from within array measurements because a finite amount of 
time is required for wind to travel from one measurement location to the other. We note however that data from PV2 support the same inference. Average within-array wind directions at PV2 are $32^{\circ}, 33^{\circ}$, and $37^{\circ}$ with standard deviations of $27^{\circ}, 27^{\circ}$, and $30^{\circ}$. In any case, the conceptual representation provided in Figure $7 \mathrm{~b}$ does not provide any insight into why wind that is incident from $0^{\circ}-30^{\circ}$ is steered towards being more aligned with the rows of solar panels, but this topic is addressed shortly.

Winds approaching from $30^{\circ}-60^{\circ}$ gave the most consistent values for attenuation. Considering anemometers at the lowest height at both PV1 and PV2, the wind speed ranged between $45 \%$ and $83 \%$ of the upwind wind speed at the same height, with 12 of the 14 anemometers giving values between $57 \%$ and $82 \%$ of upwind values. As with previous cases of winds incident at oblique angles, the within-array direction is modified by the presence of the array to be better aligned with the direction of the rows. Ignoring winds slower than $6 \mathrm{~m} \mathrm{~s}^{-1}$, the average ( \pm standard deviation) upwind wind incidence angle is $38^{\circ} \pm 6^{\circ}$. Corresponding wind directions within PV1 were $58^{\circ} \pm 9^{\circ}, 60^{\circ} \pm 8^{\circ}$, and $68^{\circ} \pm 7^{\circ}$, while within PV2 they were $64^{\circ} \pm 5^{\circ}, 66^{\circ} \pm 9^{\circ}$, and $71^{\circ} \pm 8^{\circ}$. Similar observation is made for winds approaching from $120^{\circ}-150^{\circ}$, although the range of values for attenuation is wider, with anemometers close to the underside of the panels exhibiting as little as $5 \%$ of the upwind speeds and anemometers closest to the front of a row of panels measuring wind speeds equal to $100 \%$ of the upwind values. As with the $90^{\circ}-120^{\circ}$ approach case, the near-ground winds clearly take on a northerly component indicating that the southerly component of the incident wind is reversed by the presence of the rows of solar panels.

Channeling of wind along rows of predominantly two-dimensional obstacles has been described by other investigators previously. In examining airflows in street canyons (Dobre et al., 2005; Johnson and Hunter, 1999) and dispersion in field-scale representation of street canyons (Macdonald et al., 1998; Wood et al., 2009), both with width to height ratio that was slightly greater than the present study $(\approx 2.5)$, the authors of those studies observed a clear along-canyon channeling of flow when winds were oblique to the canyon rather than perpendicular. In a series of wind tunnel experiments, Letchford (2001) measured the normal (drag) force coefficient of individual rectangular objects that were raised above ground level and intended to represent signboards. Those data indicated that for flow normal to the signboard, there are differences in drag coefficients between ground-mounted objects and those that are elevated, with the former exhibiting lower values. Letchford, (2001) also observed that when incident wind 
direction is changed from normal $\left(0^{\circ}\right)$ to oblique, the normal force coefficient is approximately constant until the flow angle of attack exceeds $\left(45^{\circ}\right)$, whence the coefficient begins to drop. Moreover, when Letchford (2001) examined the eccentricity parameter (related to torsion of signboard), it was found to peak at a $60^{\circ}$ wind approach angle. These observations suggest that when the wind achieves a certain degree of obliqueness $\left(45^{\circ}\right.$ for the Letchford (2001) case and $>30^{\circ}$ for the present study), the obstacle experiences increased torsion, meaning that it also exerts a torsional force on the wind. This is one possible explanation why winds approaching between $30^{\circ}-60^{\circ}$ and $120^{\circ}-150^{\circ}$ are steered so that the near-ground wind direction is more parallel to the rows of panels than the approach flow.

Bullard et al. (2000) used simple physical models to represent valleys in a wind tunnel study. They only examined the impact of flow direction on a single valley rather than a series of them and the width to height ratio for the model valley was greater than the present study $(\approx 5)$, so that their geometry is not directly comparable to a twodimensional solar PV array. Nevertheless, it is instructive that they found that even small deviations $\left(10^{\circ}\right)$ of wind direction from the perpendicular to a model valley resulted in significant along-valley flow in the direction of the strike of the valley that is most closely aligned with the flow, similar to what is observed in Figure 5 and Figure 6. Bullard et al. (2000) attribute this flow to the formation of a pressure gradient in the along valley direction.

Qualitatively, all of the oblique flows (i.e., not $0^{\circ}-30^{\circ}$ or $150^{\circ}-180^{\circ}$ ) can be thought of as combinations of a main component that is parallel to the rows of solar panels and a second component that either a) influences the main flow to maintain the same component in the direction perpendicular to the array through a mechanism similar to that shown in Figure $7 \mathrm{~b}$ and as is the case for the $30^{\circ}-60^{\circ}$ and $60^{\circ}-90^{\circ}$ flows or, b) influences the near-ground flow to switch directions relative to the component perpendicular to the flow through a mechanism like the one shown in Figure $7 \mathrm{a}$ and as is the case for the $90^{\circ}-120^{\circ}$ and $120^{\circ}-150^{\circ}$ wind incident angles. However, the details of these combined flows are not elucidated by the measurements presented here, neither are relevant data widely available in the literature.

Using a numerical approach (Reynolds-Averaged Navier-Stokes, RANS), the flow field over multiple rows of solar panels was rendered with considerable detail by Jubayer and Hangan (2016). Although there are some differences between the geometries of the solar panel rows that those authors consider and those of the present 
study, there is qualitative agreement between the interpretations of wind approach angle effects on the flow between consecutive arrays of solar panels. In particular, those authors also note the steering effect that we report here as a prominent feature of the flow when winds are at an oblique angle of incidence $\left(45^{\circ}\right)$ with respect to the solar panels.

\section{7}

\section{DISCUSSION AND CONCLUSIONS}

In this study, we have examined how rows of solar panels at USS facilities alter the approaching wind. This study is certainly not exhaustive in that we have not examined different geometries of USS, impacts of atmospheric stability on the results, and other potentially relevant parameters. In addition, the nature of the data collected, owing to the use of cup anemometers is somewhat limited. For example, a good accounting of the character of turbulence in between successive rows was not obtained. Therefore, the data summarized here are only helpful in understanding the mean flow at the two heights where it was measured. On the other hand, the data collected are in some ways widely representative of this type of facility. These include that the setting for the measurements was in a flat, arid landscape at a latitude where solar resources are abundant. This type of setting is ideal for siting PV USS and it is likely that $\mathrm{PV}$ facilities in such settings would be tilted at angles ranging from $15^{\circ}-35^{\circ}$, a range that is reasonably represented by the USS studied here $\left(\approx 25^{\circ}\right)$. A related point is that because such facilities are designed to reduce or eliminate subsequent rows shadowing each other (typically in winter), the relative distance (normalized to the height of the array) between successive rows is likely to span a very narrow band (on the order of $1-2$ times the net height of the solar panels). This suggests that the geometry of the USS where data were collected is probably quite representative of the average USS PV facility where panels are deployed in rows. Therefore, the information presented can be applied somewhat widely.

The data presented here provide a rough, but consistent picture of the wind flow regime close to the ground between successive rows of solar arrays, sometimes steady in response to a particular set of upwind wind conditions and sometimes fluctuating in direction, the latter suggesting that the flow is dominated by the unsteady component under certain conditions. It is tempting at this stage to use this information on mean flow field to draw conclusions about siting of solar facilities with respect to prevailing winds. For example, one could try to conclude from Figure 4 that for wind approach angles of $0^{\circ}-30^{\circ}$ the wind speed reduction at a known height, and therefore by equation 2 , the reduction in $u_{*}$ in between the panels is on the order of $30 \%-40 \%$, nearly zero for $60^{\circ}-120^{\circ}$ approach winds 
and around $60 \%$ to almost $90 \%$ for winds from $150^{\circ}-180^{\circ}$. The next conclusion using equation 1 might be that sand movement and dust emission are minimized for wind approach angles that provide the greatest attenuation of mean winds compared to the UW case. Presumably, this information could then be used to determine, given the orientation of a planned solar facility and the wind erodibility potential of the surface (using for example, methods such as those described by Fryrear et al., 1991; Etyemezian et al., 2014; Houser and Nickling, 2001; Sankey et al., 2011; and Van Pelt et al., 2010), how much wind erosion is to be expected and whether or not to apply chemical stabilizers. There are however several caveats to keep in mind when implementing this simplified treatment of dust emissions interaction with solar facilities.

As discussed previously, the reporting of $u_{*}$ in between the rows using the data that have been summarized would be of questionable quality and value for a number of reasons that include a lack of sensitivity of the anemometers used, relatively small vertical spacing given the insensitive measurements, unsteadiness of the boundary layer, and whether the vertical wind profile is representative of the "law of the wall" given the geometry of the experimental setup. Moreover, the averaging interval of 10 minutes that we used to relate wind speeds in between successive rows of solar panels to wind speeds at UW, means that those relationship are only valid at comparable time-scales. The aeolian geomorphological community has widely made use of $u_{*}$ as a principal parameter to estimate thresholds for wind erosion as well as magnitudes, and the same parameter in modified form is also used for surfaces with substantial roughness. It is important to consider that to a large degree, the prevalence of $u_{*}$ as the parameter that dictates the wind erosion behavior of a surface derives from the fact that it is comparatively easy to quantify experimentally. In both wind tunnel and field studies, $u_{*}$ is essentially a time-averaged quantity that can be estimated from measuring mean flows above the layer of roughness.

Yet, it is the air flow in the immediate vicinity of a sand grain, usually smaller than several hundred micrometers in diameter that affects whether or not it will move under the influence of aerodynamic forces, not the average flow field at some arbitrary height above the surface. Wiggs et al., (2004) argue that 40-second averaged wind speeds, measured at a location that is representative (i.e., not separated by roughness) and in the vicinity of the surface of interest, have the most explanatory power in terms of estimating and predicting a threshold for sustained sand movement. Weaver and Wiggs (2011) go a step further. Using sonic anemometry measurements along the 
centerline of a large barchan sand dune, they argue that in flows over complex geometries, traditional measurements of $u *$ or even local mean wind speeds offer little predictive capability when it comes to sand movement and that sand transport under those conditions is more related to individual components of the Reynolds stress in the vicinity of the sand grain in addition to larger features of the flow such as zones of acceleration and deceleration.

Figure 8 demonstrates several informative features of the sand movement at the USS near the PV2 instrumentation installation. The region labeled as "A" shows that in the vicinity of the vertical support structure, there is a visible clearing where sand sized particles have been removed from around larger rocks. This scouring phenomenon around the base of flow obstructions near erodible surfaces is well documented in the literature (e.g., Gillies, 2013; Gillies et al., 2007) and is an example of how the assumption of the two-dimensional (2-D) flow that is schematically depicted in Figure 7 does not hold. The assumption of 2-D flow is also violated at the edges of rows of solar panels, the perimeter of the USS facility, and near other features of the USS such as small buildings that house electrical components within the solar field. In between vertical support structures are regions of sand ridges (labeled "B" in Figure 8) that are oriented parallel to the prevailing winds (longitudinal) that often extend across several rows. They are not present in between every pair of vertical support structures, but rather appear in clusters. These observations are clear indications that sand has moved under the influence of wind. What is less clear is how much this movement constitutes a net flux of sand under the influence of wind in a specific direction and how much it constitutes a reshuffling of sand within a relatively small region in response to local effects such as acceleration and deceleration in the vicinity of vertical supports, periodic features in space and time such as vortices, and shifts in prevailing wind conditions. Examination of the region labeled " $\mathrm{C}$ " in Figure 8 indicates that sand has filled in around portions of the experimental equipment, providing evidence that sand movement was ongoing over the duration of the measurements. Transport of sand under the influence of prevailing southerly winds could explain why sand has accumulated in the top half of region $\mathrm{C}$, where there is a flow obstruction (cross brace) downstream, but cannot explain why sand has accumulated in the bottom half of region $\mathrm{C}$.

In all, this study has provided a first-order estimate of the mean wind flows in between rows of solar panels. This dataset is valuable for understanding these flows and for checking the representativeness of wind tunnel measurements and numerical modeling results. However, there remains substantial insight that is needed before this 
type of information can be used in a model that estimates the impacts of large scale solar facilities on wind erosion.

473 Notably, the fluctuating components of the flow on much shorter timescales than is presented here are critical for

474 understanding the movement of sand within and across such facilities under the influence of ambient wind. Related

475 to this, in-situ measurements of sand transport with high temporal resolution would be very useful in future work to

476 attribute the movement of sand to either a net flux in a particular direction or a local reshuffling under temporally

$477 \quad$ varying wind conditions.

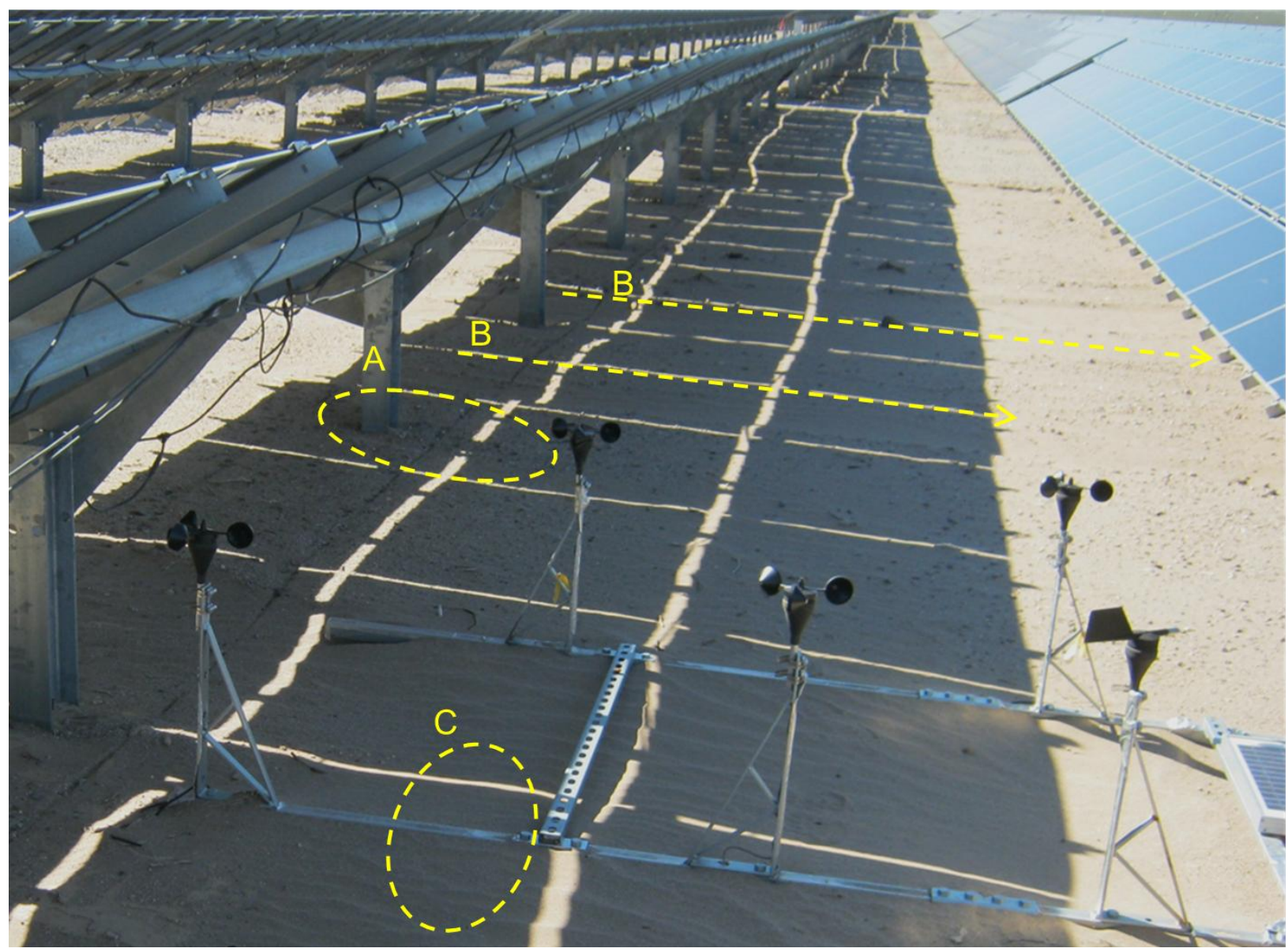

Figure 8. Patterns of sand deposition near PV2. Prevailing southerly winds flow from left to right in the 480 direction of the long arrows (B).

\section{ACKNOWLEDGEMENTS}

This material is based on work that was funded by the US Department of Energy under Grant No: DE- 
EE0000272) and the National Science Foundation under Grant No. IIA-1301726. Any opinions, findings, and conclusions or recommendations expressed in this material are those of the author(s) and do not necessarily reflect the views of the National Science Foundation or the Department of Energy. We would like to express our gratitude to SEMPRA Energy and the staff at the Copper Mountain I facility for their assistance and support during the collection of these measurements.

\section{REFERENCES}

Adinoyi, M.J., Said, S.A.M., 2013. Effect of dust accumulation on the power outputs of solar photovoltaic modules. Renew. Energy 60, 633-636. doi:10.1016/j.renene.2013.06.014

Al-Hasan, A.Y., Ghoneim, A.A., 2005. A new correlation between photovoltaic panel's efficiency and amount of sand dust accumulated on their surface. Int. J. Sustain. Energy 24, 187-197. doi:10.1080/14786450500291834

Appels, R., Lefevre, B., Herteleer, B., Goverde, H., Beerten, A., Paesen, R., De Medts, K., Driesen, J., Poortmans, J., 2013. Effect of soiling on photovoltaic modules. Sol. Energy 96, 283-291. doi:10.1016/j.solener.2013.07.017

Bagnold, R.A., 1941. The physics of blown sand and desert dunes,. Methuen \& Co., London. Bearman, P.W., 1971. Investigation of Forces on Flat Plates Normal to a Turbulent Flow. J. Fluid Mech. 46, 177-198.

Boyle, L., Flinchpaugh, H., Hannigan, M.P., 2015. Natural soiling of photovoltaic cover plates and the impact on transmission. Renew. Energy 77, 166-173. doi:10.1016/j.renene.2014.12.006

Bullard, J.E., Wiggs, G.F.S., Nash, D.J., 2000. Experimental study of wind directional variability in the vicinity of a model valley. Geomorphology 35, 127-143.

Cabanillas, R.E., Munguía, H., 2011. Dust accumulation effect on efficiency of Si photovoltaic modules. J. Renew. Sustain. Energy 3, 43114.

Castro, I.P., 1981. Measurements in shear layers separating from surface-mounted bluff bodies. J. Wind Eng. Ind. Aerodyn. 7, 253-272.

Charabi, Y., Gastli, A., 2012. Spatio-temporal assessment of dust risk maps for solar energy systems using proxy data. Renew. Energy 44, 23-31. doi:10.1016/j.renene.2011.12.005

D. W. Fryrear, J. E. Stout, L. J. Hagen, E. D. Vories, 1991. Wind Erosion: Field Measurement And Analysis. Trans. ASAE 34, 155. doi:10.13031/2013.31638

Dobre, A., Arnold, S.J., Smalley, R.J., Boddy, J.W.D., Barlow, J.F., Tomlin, A.S., Belcher, S.E., 2005. Flow field measurements in the proximity of an urban intersection in London, UK. Atmos. Environ. 39, 4647-4657. doi:10.1016/j.atmosenv.2005.04.015

El-Shobokshy, M., Hussein, F., 1993. Effect of Dust with Different Physical Properties on the Performance of Photovoltaic Cells. Sol. Energy 51, 505-511.

Etyemezian, V., Gillies, J.A., Shinoda, M., Nikolich, G., King, J., Bardis, A.R., 2014. Accounting for surface roughness on measurements conducted with PI-SWERL: Evaluation of a subjective visual approach and a photogrammetric technique. Aeolian Res. 13, 35-50. doi:10.1016/j.aeolia.2014.03.002

Fuentealba, E., Ferrada, P., Araya, F., Marzo, A., Parrado, C., Portillo, C., 2015. Photovoltaic performance and LCoE comparison at the coastal zone of the Atacama Desert, Chile. 
Energy Convers. Manag. 95, 181-186. doi:10.1016/j.enconman.2015.02.036

Ghazi, S., Sayigh, A., Ip, K., 2014. Dust effect on flat surfaces - A review paper. Renew. Sustain. Energy Rev. 33, 742-751. doi:10.1016/j.rser.2014.02.016

Giannoulis, A., Stathopoulos, T., Briassoulis, D., Mistriotis, A., 2012. Wind loading on vertical panels with different permeabilities. J. Wind Eng. Ind. Aerodyn. 107-108, 1-16. doi:10.1016/j.jweia.2012.02.014

Gillies, J., 2013. Fundamentals of aeolian sediment transport | Dust emissions and transport near surface, in: Treatise on Geomorphology. Academic Press, San Diego, California, pp. 43-63.

Gillies, J.A., Nickling, W.G., King, J., 2007. Shear stress partitioning in large patches of roughness in the atmospheric inertial sublayer. Bound.-Layer Meteorol. 122, 367-396. doi:10.1007/s10546-006-9101-5

Gomes, L., Bergametti, G., Coudegaussen, G., Rognon, P., 1990. Submicron Desert Dusts - a Sandblasting Process. J. Geophys. Res.-Atmospheres 95, 13927-13935. doi:10.1029/JD095iD09p13927

Goossens, D., Offer, Z.Y., Zangvil, A., 1993. Wind tunnel experiments and field investigations of eolian dust deposition on photovoltaic solar collectors. Sol. Energy 50, 75-84. doi:10.1016/0038-092X(93)90009-D

Goossens, D., Van Kerschaever, E., 1999. Aeolian dust deposition on photovoltaic solar cells: the effects of wind velocity and airborne dust concentration on cell performance. Sol. Energy 66, 277-289.

Hegazy, A.A., 2001. Effect of dust accumulation on solar transmittance through glass covers of plate-type collectors. Renew. Energy 22, 525-540.

Hernandez, R.R., Easter, S.B., Murphy-Mariscal, M.L., Maestre, F.T., Tavassoli, M., Allen, E.B., Barrows, C.W., Belnap, J., Ochoa-Hueso, R., Ravi, S., Allen, M.F., 2014. Environmental impacts of utility-scale solar energy. Renew. Sustain. Energy Rev. 29, 766-779. doi:10.1016/j.rser.2013.08.041

Houser, C.A., Nickling, W.G., 2001. The emission and vertical flux of particulate matter $<10 \mu \mathrm{m}$ from a disturbed clay-crusted surface. Sedimentology 48, 255-267. doi:10.1046/j.13653091.2001.00359.x

Jacobs, A.F.G., 1984. Wind reduction near the surface behind a thin solid fence. Agric. For. Meteorol. 33, 157-162.

Johnson, G.., Hunter, L.J., 1999. Some insights into typical urban canyon airflows. Atmos. Environ. 33, 3991-3999.

Jubayer, C.M., Hangan, H., 2016. A numerical approach to the investigation of wind loading on an array of ground mounted solar photovoltaic (PV) panels. J. Wind Eng. Ind. Aerodyn. 153, 60-70. doi:10.1016/j.jweia.2016.03.009

Judd, M.J., Raupach, M.R., Finnigan, J.J., 1996. A wind tunnel study of turbulent flow around single and multiple windbreaks, part I: velocity fields. Bound.-Layer Meteorol. 80, 127165.

Kalogirou, S.A., Agathokleous, R., Panayiotou, G., 2013. On-site PV characterization and the effect of soiling on their performance. Energy 51, 439-446. doi:10.1016/j.energy.2012.12.018

Kavouras, I.G., Etyemezian, V., Nikolich, G., Gillies, J., Sweeney, M., Young, M., Shafer, D., 2009. A New Technique for Characterizing the Efficacy of Fugitive Dust Suppressants. J. 
Air Waste Manag. Assoc. 59, 603-612. doi:10.3155/1047-3289.59.5.603

Khonkar, H., Alyahya, A., Aljuwaied, M., Halawani, M., Al Saferan, A., Al-khaldi, F., Alhadlaq, F., Wacaser, B.A., 2014. Importance of cleaning concentrated photovoltaic arrays in a desert environment. Sol. Energy 110, 268-275. doi:10.1016/j.solener.2014.08.001

King, J., Etyemezian, V., Sweeney, M., Buck, B.J., Nikolich, G., 2011. Dust emission variability at the Salton Sea, California, USA. Aeolian Res. 3, 67-79. doi:10.1016/j.aeolia.2011.03.005

Klugmann-Radziemska, E., 2015. Degradation of electrical performance of a crystalline photovoltaic module due to dust deposition in northern Poland. Renew. Energy 78, 418426. doi:10.1016/j.renene.2015.01.018

Kristensen, L., 1998. Cup anemometer behavior in turbulent environments. J. Atmospheric Ocean. Technol. 15, 5-17.

Letchford, C.W., 2001. Wind loads on rectangular signboards and hoardings. J. Wind Eng. Ind. Aerodyn. 89, 135-151.

Loosmore, G.A., Hunt, J.R., 2000. Dust resuspension without saltation. J. Geophys. Res.Atmospheres 105, 20663-20671. doi:10.1029/2000JD900271

Lu, H., Raupach, M.R., Richards, K.S., 2005. Modeling entrainment of sedimentary particles by wind and water: A generalized approach. J. Geophys. Res. 110. doi:10.1029/2005JD006418

Macdonald, R.W., Griffiths, R.F., Hall, D.J., 1998. A comparison of results from scaled field and wind tunnel modelling of dispersion in arrays of obstacles. Atmos. Environ. 32, 38453862.

Macpherson, T., Nickling, W.G., Gillies, J.A., Etyemezian, V., 2008. Dust emissions from undisturbed and disturbed supply-limited desert surfaces. J. Geophys. Res.-Earth Surf. 113, F02S04. doi:10.1029/2007JF000800

Mani, M., Pillai, R., 2010. Impact of dust on solar photovoltaic (PV) performance: Research status, challenges and recommendations. Renew. Sustain. Energy Rev. 14, 3124-3131. doi:10.1016/j.rser.2010.07.065

McAneney, K.J., Judd, M.J., 1991. Multiple windbreaks: an aeolean ensemble. Bound.-Layer Meteorol. 54, 129-146.

Michels, R.N., Canteri, M.G., Silva, M.A. de A. e, Gnoatto, E., Santos, J.A.A. dos, Jesus, M.M.A. de, 2015. Yield from photovoltaic modules under real working situations in west Paraná - Brazil. Acta Sci. Technol. 37, 19. doi:10.4025/actascitechnol.v37i1.19191

Piliougine, M., Cañete, C., Moreno, R., Carretero, J., Hirose, J., Ogawa, S., Sidrach-de-Cardona, M., 2013. Comparative analysis of energy produced by photovoltaic modules with antisoiling coated surface in arid climates. Appl. Energy 112, 626-634. doi:10.1016/j.apenergy.2013.01.048

Qasem, H., Betts, T.R., Müllejans, H., AlBusairi, H., Gottschalg, R., 2014. Dust-induced shading on photovoltaic modules: Dust-induced shading on photovoltaic modules. Prog. Photovolt. Res. Appl. 22, 218-226. doi:10.1002/pip.2230

Raine, J.K., Stevenson, D.C., 1977. Wind protection by model fences in a simulated atmospheric boundary layer. J. Ind. Aerodyn. 2, 159-180.

Raupach, M., Gillette, D., Leys, J., 1993. The Effect of Roughness Elements on Wind Erosion Threshold. J. Geophys. Res.-Atmospheres 98, 3023-3029. doi:10.1029/92JD01922

Said, S.A.M., Walwil, H.M., 2014. Fundamental studies on dust fouling effects on PV module 
performance. Sol. Energy 107, 328-337. doi:10.1016/j.solener.2014.05.048

Sankey, J.B., Eitel, J.U.H., Glenn, N.F., Germino, M.J., Vierling, L.A., 2011. Quantifying relationships of burning, roughness, and potential dust emission with laser altimetry of soil surfaces at submeter scales. Geomorphology 135, 181-190. doi:10.1016/j.geomorph.2011.08.016

Santiago, J.L., Martín, F., Cuerva, A., Bezdenejnykh, N., Sanz-Andrés, A., 2007. Experimental and numerical study of wind flow behind windbreaks. Atmos. Environ. 41, 6406-6420. doi:10.1016/j.atmosenv.2007.01.014

Sarver, T., Al-Qaraghuli, A., Kazmerski, L.L., 2013. A comprehensive review of the impact of dust on the use of solar energy: History, investigations, results, literature, and mitigation approaches. Renew. Sustain. Energy Rev. 22, 698-733. doi:10.1016/j.rser.2012.12.065

Sayyah, A., Horenstein, M.N., Mazumder, M.K., 2014. Energy yield loss caused by dust deposition on photovoltaic panels. Sol. Energy 107, 576-604. doi:10.1016/j.solener.2014.05.030

Schellenberg, A., Maffei, J., Telleen, K., Ward, R., 2013. Structural analysis and application of wind loads to solar arrays. J. Wind Eng. Ind. Aerodyn. 123, 261-272. doi:10.1016/j.jweia.2013.06.011

Schill, C., Brachmann, S., Koehl, M., 2015. Impact of soiling on IV-curves and efficiency of PVmodules. Sol. Energy 112, 259-262. doi:10.1016/j.solener.2014.12.003

Shademan, M., Barron, R.M., Balachandar, R., Hangan, H., 2014. Numerical simulation of wind loading on ground-mounted solar panels at different flow configurations. Can. J. Civ. Eng. 41, 728-738. doi:10.1139/cjce-2013-0537

Shao, Y., 2001. A model for mineral dust emission. J. Geophys. Res.-Atmospheres 106, 2023920254. doi:10.1029/2001JD900171

Shao, Y., Raupach, M., 1993. Effect of Saltation Bombardment on the Entrainment of Dust by Wind. J. Geophys. Res.-Atmospheres 98, 12719-12726. doi:10.1029/93JD00396

Shao, Y., Yang, Y., 2008. A theory for drag partition over rough surfaces. J. Geophys. Res. Earth Surf. 113, F02S05. doi:10.1029/2007JF000791

Stathopoulos, T., Zisis, I., Xypnitou, E., 2014. Local and overall wind pressure and force coefficients for solar panels. J. Wind Eng. Ind. Aerodyn. 125, 195-206. doi:10.1016/j.jweia.2013.12.007

Sweeney, M.R., McDonald, E.V., Etyemezian, V., 2011. Quantifying dust emissions from desert landforms, eastern Mojave Desert, USA. Geomorphology 135, 21-34. doi:10.1016/j.geomorph.2011.07.022

Tanabe, K., 2008. Modeling of airborne dust accumulation on solar cells at the Martian surface. Acta Astronaut. 62, 683-685. doi:10.1016/j.actaastro.2008.01.036

Touati, F.A., Al-Hitmi, M.A., Bouchech, H.J., 2013. Study of the Effects of Dust, Relative Humidity, and Temperature on Solar PV Performance in Doha: Comparison Between Monocrystalline and Amorphous PVS. Int. J. Green Energy 10, 680-689. doi:10.1080/15435075.2012.692134

Van Pelt, R.S., Zobeck, T.M., Baddock, M.C., Cox, J.J., 2010. Design, Construction, and Calibration of a Portable Boundary Layer Wind Tunnel for Field Use. Trans. ASABE 53, 1413-1422. doi:10.13031/2013.34911

Vivar, M., Herrero, R., Moreton, R., Martinez-Moreno, F., Sala, G., 2008. Effect of soiling on PV Concentrators: Comaprison with flat modules, in: IEEE. 
Warsido, W.P., Bitsuamlak, G.T., Barata, J., Gan Chowdhury, A., 2014. Influence of spacing parameters on the wind loading of solar array. J. Fluids Struct. 48, 295-315. doi:10.1016/j.jfluidstructs.2014.03.005

Weaver, C.M., Wiggs, G.F.S., 2011. Field measurements of mean and turbulent airflow over a barchan sand dune. Geomorphology 128, 32-41. doi:10.1016/j.geomorph.2010.12.020

Wiggs, G.F.S., Atherton, R.J., Baird, A.J., 2004. Thresholds of aeolian sand transport: establishing suitable values. Sedimentology 51, 95-108. doi:10.1046/j.13653091.2003.00613.x

Wilson, J., Yee, E., 2003. Calculation of winds disturbed by an array of fences. Agric. For. Meteorol. 115, 31-50.

Wilson, J.D., 2004. Oblique, stratified winds about a shelter fence. Part I: Measurements. J. Appl. Meteorol. 43, 1149-1167.

Wood, C.R., Barlow, J.F., Belcher, S.E., Dobre, A., Arnold, S.J., Balogun, A.A., Lingard, J.J.N., Smalley, R.J., Tate, J.E., Tomlin, A.S., Britter, R.E., Cheng, H., Martin, D., Petersson, F.K., Shallcross, D.E., White, I.R., Neophytou, M.K., Robins, A.G., 2009. Dispersion Experiments in Central London: The 2007 DAPPLE project. Bull. Am. Meteorol. Soc. 90, 955-969. doi:10.1175/2009BAMS2638.1

Wyngaard, J.C., 1981. Cup, propeller, vane, and sonic anemometers in turbulence research. Annu. Rev. Fluid Mech. 13, 399-423.

Xiao, J., Yao, Z., Qu, J., Sun, J., 2013. Research on an optimal site selection model for desert photovoltaic power plants based on analytic hierarchy process and geographic information system. J. Renew. Sustain. Energy 5, 23132.

Zhang, J., Shao, Y., 2014. A new parameterization of particle dry deposition over rough surfaces. Atmospheric Chem. Phys. 14, 12429-12440. doi:10.5194/acp-14-12429-2014

Zorrilla-Casanova, J., Piliougine, M., Carretero, J., Bernaola-Galván, P., Carpena, P., MoraLópez, L., Sidrach-de-Cardona, M., 2012. Losses produced by soiling in the incoming radiation to photovoltaic modules: Losses produced by soiling in the incoming radiation to PV modules. Prog. Photovolt. Res. Appl. 790-796. doi:10.1002/pip.1258 